\title{
Pressure Transient Behavior of Horizontal Well with Time-Dependent Fracture Conductivity in Tight Oil Reservoirs
}

\author{
Qihong Feng, ${ }^{1}$ Tian Xia, ${ }^{1}$ Sen Wang, ${ }^{1}$ and Harpreet Singh ${ }^{2}$ \\ ${ }^{1}$ School of Petroleum Engineering, China University of Petroleum (East China), Qingdao 266580, China \\ ${ }^{2}$ Department of Petroleum and Geosystems Engineering, The University of Texas at Austin, Austin, TX, USA \\ Correspondence should be addressed to Sen Wang; fwforest@gmail.com
}

Received 9 June 2017; Revised 29 July 2017; Accepted 7 August 2017; Published 28 September 2017

Academic Editor: Jianchao Cai

Copyright ( 2017 Qihong Feng et al. This is an open access article distributed under the Creative Commons Attribution License, which permits unrestricted use, distribution, and reproduction in any medium, provided the original work is properly cited.

\begin{abstract}
This work presents a discussion on the pressure transient response of multistage fractured horizontal well in tight oil reservoirs. Based on Green's function, a semianalytical model is put forward to obtain the behavior. Our proposed model accounts for fluid flow in four contiguous regions of the tight formation by using pressure continuity and mass conservation. The time-dependent conductivity of hydraulic fractures, which is ignored in previous models but highlighted by recent experiments, is also taken into account in our proposed model. We also include the effect of pressure drop along a horizontal wellbore. We substantiate the validity of our model and analyze the different flow regimes, as well as the effects of initial conductivity, fracture distribution, and geometry on the pressure transient behavior. Our results suggest that the decrease of fracture conductivity has a tremendous effect on the well performance. Finally, we compare our model results with the field data from a multistage fractured horizontal well in Jimsar sag, Xinjiang oilfield, and a good agreement is obtained.
\end{abstract}

\section{Introduction}

Unconventional resources are playing increasingly important roles in the energy industry $[1,2]$. We have witnessed a great success in North America $[3,4]$. Owing to its extremely low permeability [5], tight oil could not be economically developed via conventional technology [6-8]. Multistage fractured horizontal well (MFHW) is an efficient technique in the development of unconventional reserves [9]. However, analyzing the pressure response of multifractured horizontal wells is challenging because several factors, for example, fracture conductivity, fracture geometry, skew angle between fracture, and horizontal well, are responsible for the pressure transient behavior. Therefore, the variation of pressure as a function of these factors is still ambiguous.

Pressure transient analysis is an important tool to estimate the formation characteristics. Significant efforts have been dedicated in proposing models to describe the process. Gringarten and Ramey Jr. analyzed the transient behavior of uniform-flux fracture and infinite-conductivity fracture well through source function method [10]. Cinco-Ley and
Samaniego developed a mathematical model for finiteconductivity fracture [11]. Then Cinco-Ley and Meng gave the solution for wells with finite-conductivity fractures in Laplace domain [12]. Ozkan and Raghavan employed point-source solution method to get transient pressure solutions under a variety of conditions [13]. Although these studies only dealt with a single fracture, they have laid a solid foundation for the analysis of pressure behavior in multiple fractures.

The tools that are commonly used to make the transient pressure analysis of multiple fractures can be divided into three categories: analytical, semianalytical, and numerical method. Guo et al. developed an analytical method for horizontal well intersecting multiple fractures [14]. However, the interference of the fractures was neglected. Wan and Aziz derived an analytical 3D solution for horizontal well with multiple random fractures by using Fourier analysis to a $2 \mathrm{D}$ solution [15]. Ozkan et al. proposed a trilinear flow model, in which the linear flow in outer reservoir, inner reservoir, and hydraulic fractures are included [16]. Brown et al. improved this model to simulate the pressure transient and production behaviors of fractured horizontal wells in unconventional 
TABLE 1: Background information for the experimental studies on the variation of fracture conductivity with time.

\begin{tabular}{lcc}
\hline Author & Material & Confining stress \\
\hline McDaniel (1986) & Sand, resin coated sand, and three ceramic proppants & 8000 psi \\
Cobb and Farrell (1986) & Ceramic proppants & 10000 psi and 5000 psi \\
Handren and Palisch (2007) & Sand and resin coated sand & 6000 psi \\
\hline
\end{tabular}

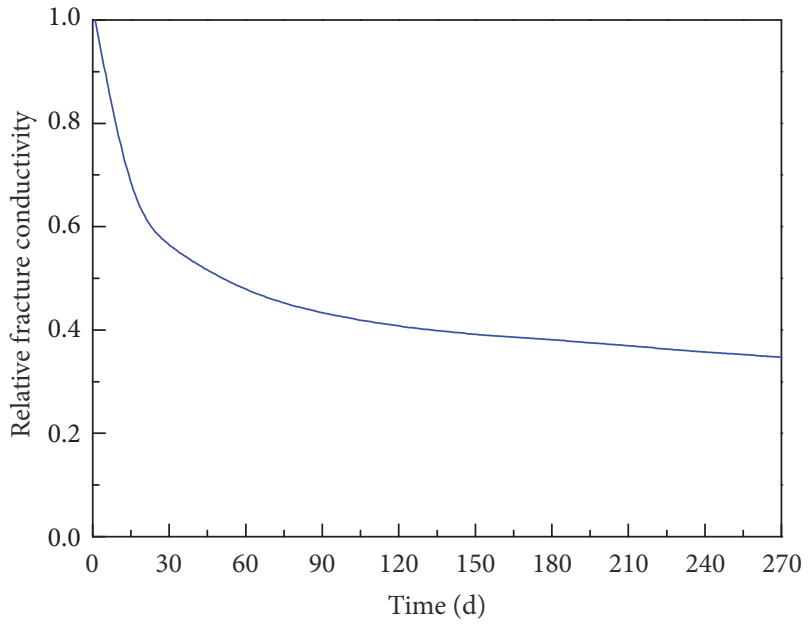

FIGURE 1: Schematic showing the variation of relative fracture conductivity with time (Montgomery, 1984).

shale reservoirs [17]. Al Rbeawi and Djebbar introduced a new analytical model that can be used to investigate the pressure behavior and flow regimes of a horizontal well with multiple inclined hydraulic fractures and applied it in type curve matching [18].

Semianalytical approaches are another important way in analyzing the transient behavior. Horne and Temeng considered the interference among the fractures via the superposition of influence functions [19]. Zerzar and Bettam combined the boundary element method and Laplace transformation to deal with interaction of reservoir flow and fracture flow [20]. Yao et al. presented a method based on Green's functions and the source/sink method to obtain the transient pressure response for a multifractured horizontal well in a closed box-shaped reservoir [21]. Zhou et al. proposed a semianalytical model to simulate the pressure transient behavior in complex hydraulic fracture networks [22]. Yu combined gas desorption and Zhou et al's model to solve the gas production problem in shale gas reservoir [23]. Jia et al. presented a model to solve the transient behavior in complex fracture networks with deep consideration for flow in fractures [24].

Numerical approaches overcome many limitations in analytical and semianalytical method in studying unconventional reservoirs. Al-Kobaisi et al. presents a hybrid, numerical-analytical model for the pressure transient response of a finite-conductivity fracture intercepted by a horizontal well [25]. Freeman et al. used numerical sensitivity studies to show the effect of mechanisms and factors on the performance of multifractured horizontal well [26-28]. Olorode et al. employed numerical method to study the effect of fracture angularity and nonplanar fracture configurations on well performance [29]. Yu et al. conducted numerical simulation to investigate the impact of fracture patterns, matrix permeability, cluster spacing, and fracture conductivity [30].

In previous studies, the conductivity of hydraulic fractures was often assumed to be uniformly distributed and remained constant with time. However, this assumption contradicted field practice. After hydraulic fracturing, the fractures close rapidly. In order to mitigate the production decrease, proppants are added in the fracturing fluid to prop the fracture and maintain the productivity. However, this operation can only alleviate the decrease rate of the fracture conductivity. The conductivity will eventually decrease [3134]. Previous studies suggest that the fracture conductivity decreases rapidly during the first couple of days and for the rest of the time the decline degree remains very small (Figure 1).

Table 1 shows some experiments that studied the variation of fracture conductivity with time. McDaniel reported that the sand lost $80 \%$ of the conductivity within 15 days, among which the resin coated sand lost $55 \%$, and ceramic proppants lost 25\% to 30\% [35]. Tests by Cobb and Farrell showed that ceramic proppants lost $\sim 20 \%$ of conductivity in 70 days when confined at $10000 \mathrm{psi}$ and the sand lost over $30 \%$ when confined at 5000 psi [36]. Handren and Palisch reported decline in the conductivity with sands losing $55 \%$ and resin coated sand losing 25\% to 30\% [37]. Because the production rate is strongly dependent on the fracture conductivity, its variation with time must be taken into account to accurately predict the well performance.

Contrary to the reported observations, many studies have assumed horizontal well to be of infinite conductivity [16, $24,38]$. This assumption is not reliable as it cannot reflect the radial influx, frictional, and acceleration effects. It is necessary to examine the effect of pressure drop within the wellbore on the production performance.

The objective of this study is to examine the effect of timedependent fracture conductivity on the transient behavior of MFHW. As shown in Figure 2(a), some hydraulic fractures are not perpendicular to the horizontal wellbore, which contradicts the common assumption in the analytical models. That is, the pressure transient behavior of this complex fracture network is not readily to be analytically accounted for. Therefore, we present a semianalytical model to take into account the time-dependent fracture conductivity and the pressure drop along a horizontal wellbore, as well as the complex fracture networks. 


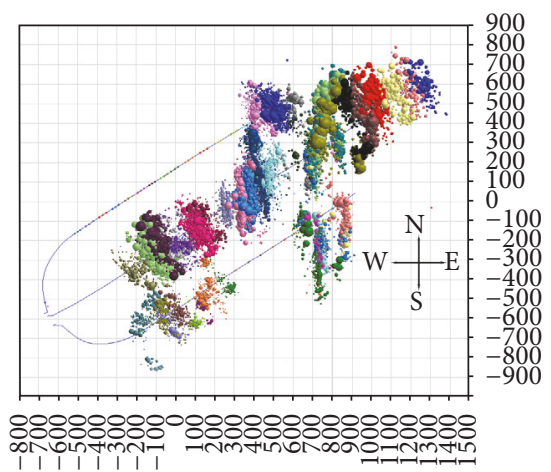

(a)

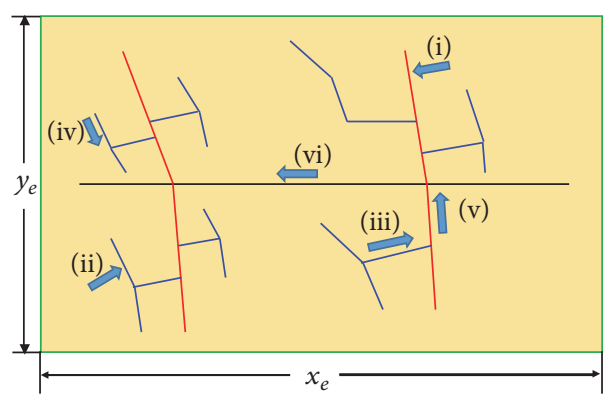

(b)

FIgURE 2: (a) Microseismic data showing the complex fractures in Jimsar sag, Xinjiang oilfield. (b) Schematic of a fracture network. The black, red, and blue lines represent the wellbore, hydraulic fractures, and natural fractures, respectively.

\section{Methodology}

2.1. Mathematical Model. The reservoir after fracturing includes four regions: the matrix, the natural fracture network, hydraulic fractures, and the horizontal wellbore. Therefore, the fluid flow in the reservoir consists of (1) fluid flow from the reservoir to the hydraulic fractures ((i) in Figure 2(b)); (2) fluid flow from the reservoir to the natural fractures ((ii) in Figure 2(b)); (3) fluid flow from natural fracture to hydraulic fractures ((iii) in Figure 2(b)); (4) fluid flow among natural fractures ((iv) in Figure 2(b)); (5) fluid form hydraulic fractures to the horizontal wellbore ((v) in Figure 2(b)); (6) fluid flow in the horizontal wellbore ((vi) in Figure 2(b)). These six types of flow can be categorized into three groups: reservoir flow ((i) and (ii) in Figure 2(b)), fracture flow ((iii), (iv), and (v) in Figure 2(b)), and wellbore flow ((vi) in Figure 2(b)).

Following assumptions are made:

(1) Reservoir is isotropic, homogeneous, box-shaped, and of uniform thickness with impermeable boundaries.

(2) Fluid in the reservoir is single-phase and slightly compressible and its compressibility and viscosity are constant.

(3) Fractures are rectangular and vertical. The flux rate is uniform along the fracture.

(4) Horizontal well is parallel to the upper and lower boundary of the reservoir.

(5) Effect of gravity is neglected.

First, we define some dimensionless parameters for generality. The dimensionless pressure and time can be defined as

$$
\begin{aligned}
& p_{D}=\frac{2 \pi \rho k h}{Q \mu}\left(p_{i}-p\right), \\
& t_{D}=\frac{k t}{\phi \mu C_{t} L^{2}} .
\end{aligned}
$$

The dimensionless flow rate and influx rate can be defined as

$$
\begin{gathered}
q_{D}=\frac{q}{Q}, \\
q_{f D}=\frac{q_{f}}{Q} L .
\end{gathered}
$$

The dimensionless length along $x$ and $y$ directions can be defined as

$$
\begin{aligned}
& x_{D}=\frac{x}{L}, \\
& y_{D}=\frac{y}{L} .
\end{aligned}
$$

2.1.1. Reservoir Flow. We use Green's function that has been frequently applied to solve problems of transient flow since its usage was first explored in well testing by Gringarten and Ramey Jr. [10]. Based on the Newman product method, instantaneous source functions of fracture panels can be obtained; therefore, the pressure response at any point in the reservoir from one fracture panel can be expressed as follows (see Appendix for further details):

$$
\begin{aligned}
\Delta p(x, y, z, t) & =p_{i}-p(x, y, z, t) \\
& =\frac{1}{\phi C_{t}} \int_{0}^{t} q_{f j}(t-\tau) S_{j}(x, y, z, \tau) d \tau,
\end{aligned}
$$

where $S_{j}(x, y, z, \tau)$ is the instantaneous plane source function of the $j$ th panel and $p_{i}$ is the initial reservoir pressure which is assumed to be uniformly distributed in the reservoir.

For fracture $j$ rotated at any horizontal angle to the well, the plane source function is

$$
\begin{aligned}
& S_{j}(x, y, z)=\frac{1}{x_{e} y_{e} z_{e}} \int_{x_{j 1}}^{x_{j 2}} \int_{0}^{z_{e}}[1 \\
& \left.\quad+2 \sum_{n=1}^{\infty} \exp \left(-\frac{n^{2} \pi^{2} \eta_{x} t}{x_{e}^{2}}\right) \cos n \pi \frac{x^{\prime}}{x_{e}} \cos n \pi \frac{x}{x_{e}}\right] \cdot[1 \\
& \left.\quad+2 \sum_{n=1}^{\infty} \exp \left(-\frac{n^{2} \pi^{2} \eta_{y} t}{y_{e}^{2}}\right) \cos n \pi \frac{x^{\prime} \tan \theta_{j}}{y_{e}} \cos n \pi \frac{y}{y_{e}}\right]
\end{aligned}
$$




$$
\begin{aligned}
& \cdot\left[1+2 \sum_{n=1}^{\infty} \exp \left(-\frac{n^{2} \pi^{2} \eta_{z} t}{z_{e}^{2}}\right) \cos n \pi \frac{z^{\prime}}{z_{e}}\right. \\
& \left.\cdot \cos \frac{n \pi z}{z_{e}}\right] d x^{\prime} d z^{\prime}
\end{aligned}
$$

By using the superposition principle, pressure at any point in the reservoir at a given time can be given by

$$
\begin{aligned}
\Delta p(x, y, z, t) & =p_{i}-p(x, y, z, t) \\
& =\frac{1}{\phi C} \sum_{j=1}^{N_{p}} \int_{0}^{t} q_{f j}(t-\tau) S_{j}(x, y, z, \tau) d \tau .
\end{aligned}
$$

Then we can get the dimensionless form of (6),

$$
\begin{aligned}
p_{D} & \left(x_{D}, y_{D}, z_{D}, t_{D}\right) \\
& =2 \pi \sum_{j=1}^{N_{p}} \int_{0}^{t_{D}} q_{f j D}\left(t_{D}-\tau_{D}\right) S_{j D}\left(x_{D}, y_{D}, z_{D}, \tau_{D}\right) d \tau_{D} .
\end{aligned}
$$

Therefore, pressure map can be obtained at a given time.

2.1.2. Fracture Flow. We assume that each hydraulic fracture is of finite-conductivity and fluid flow inside the fracture is one dimensional $[17,39-41]$. We use Darcy's equation to describe the fluid flow in fractures. For the $j$ th panel, the pressure at any point in the fracture is (see Appendix for further details):

$$
\begin{aligned}
p_{j 1} & -p_{j m} \\
= & \int_{x_{j 1}}^{x_{j m}}\left(\frac{\mu}{\rho k_{f} b_{f} h}\right)_{j}\left[q_{j 1}+q_{f j}\left(x-x_{j 1}\right)\right] d x .
\end{aligned}
$$

Then the dimensionless form is

$$
\begin{aligned}
& p_{j m D}-p_{j 1 D} \\
& \quad=\frac{2 \pi k L}{k_{f} b_{f}} \int_{x_{j 1 D}}^{x_{j m D}}\left[q_{j 1 D}+q_{f j D}\left(x_{D}-x_{j 1 D}\right)\right] d x_{D} .
\end{aligned}
$$

Equations (8) and (9) can be applied to both hydraulic fractures and natural fractures.

It is worth noting that fluid flow from the fractures to the horizontal wellbore is radial in the near-well region (Figure 3). In order to minimize the error caused by linear flow approximation, a choke flow factor is introduced [42]:

$$
s_{c}=\left(\frac{h}{2 \pi x_{e}}\right)\left[\ln \left(\frac{h}{2 r_{w}}\right)-\frac{\pi}{2}\right],
$$

where $r_{w}$ is the radius of the horizontal well and $b_{f}$ is the hydraulic fracture width.

2.1.3. Time-Dependent Conductivity. Proppants are often pumped into the formation to maintain the fracture conductivity. However, the proppant particles usually break and

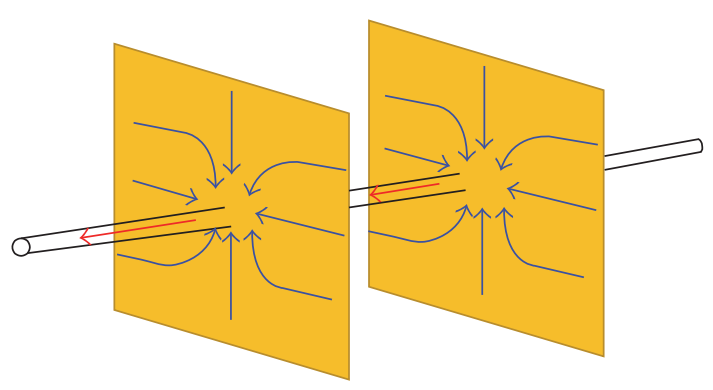

FIGURE 3: Sketch showing the change of flow pattern from linear to radial.

embed, which causes the fracture conductivity to reduce until equilibrium is established. Montgomery and Steanson suggested that there is a logarithmic relation between hydraulic fracture conductivity and time for 10/20 Sand and 20/40 Sand (Figure 4(a)) [43]. Other tests also show logarithmic relation between fracture conductivity and time, including Lanzhou sand from China with diameter of $0.45 \sim 0.90 \mathrm{~mm}$ [44], and sand from Shanshan oil field in China (Figure 4(c)) [45]. Other kinds of proppants such as ceramic proppants with diameter of $0.45 \sim 0.9 \mathrm{~mm}$ and Lanzhou sand with diameter of $0.9 \sim 1.25 \mathrm{~mm}$ show similar correlations, but the slope of the curve, also referred to as the decline coefficient, for each proppant is different. The decline coefficient decreases in the order of Lanzhou sand with diameter of $0.90 \sim 1.25 \mathrm{~mm}$, the ceramic proppant, and the Lanzhou sand with smaller diameter.

Based on the trend of observations in Figure 4, we use the following model to describe the variation of fracture conductivity as a function of time,

$$
C_{f}=C_{f 0}\left(1-\beta \lg \frac{t}{t_{0}}\right),
$$

where $C_{f}$ is the fracture conductivity at time $t, C_{f 0}$ is the initial conductivity, and $\beta$ is the decline coefficient. $C_{f}$ in (11) is substituted by $k_{f} \cdot b_{f}$ in (8) and (9). It is assumed that when the effect of hydraulic fracture disappears totally, the fracture conductivity is equal to the product of formation permeability and fracture width.

2.1.4. Wellbore Flow. Previous studies assumed horizontal wellbore as infinite-conductivity pipe $[15,16]$, which implicitly assumes no pressure drop along the horizontal well because of uniform pressure distribution along the wellbore. To examine the validity of this approximation, we include the wellbore pressure drop in the present model. The pressure decrease along the wellbore consists of frictional losses and acceleration losses (Figure 5). Based on the Darcy-Weisbach Equation [46], the fictional pressure drop can be expressed as

$$
\Delta p_{\text {fric }}=\frac{f_{i}}{2} \frac{\Delta l_{i}}{D_{i}} \rho_{i} v_{i}^{2},
$$

where $f_{i}$ is the frictional coefficient and $\Delta l_{i}$ is the length of the wellbore segment. For each segment of the wellbore, fluid flow from the hydraulic fractures to the wellbore will cause an 


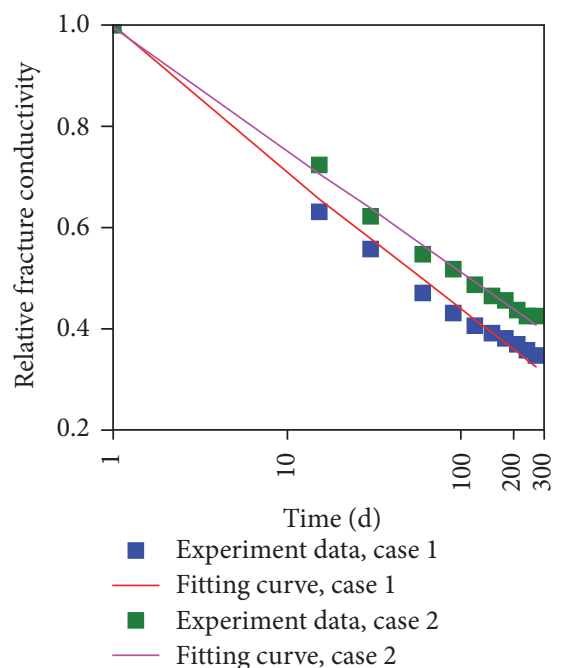

(a)

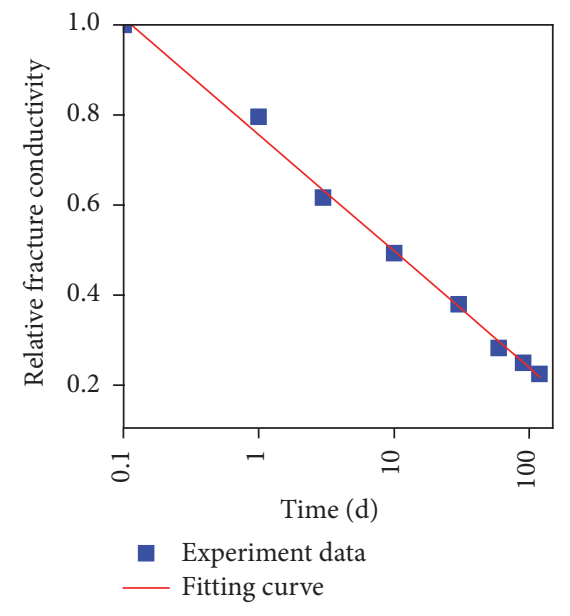

(b)

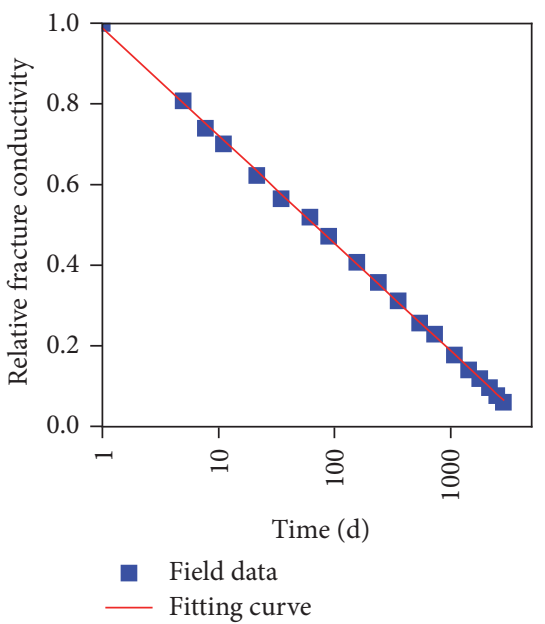

(c)

FIGURE 4: Relation between relative fracture conductivity and time. (a) Montgomery and Steanson (1985) tested two samples with different kind of proppants for 9 months, case 1 denotes $10 / 20$ Sand at $250^{\circ} \mathrm{F}$, and case 2 denotes $20 / 40$ Sand at $75^{\circ} \mathrm{F}$. (b) Experiment conducted by Yu (1987). (c) Field data from Shanshan oilfield.

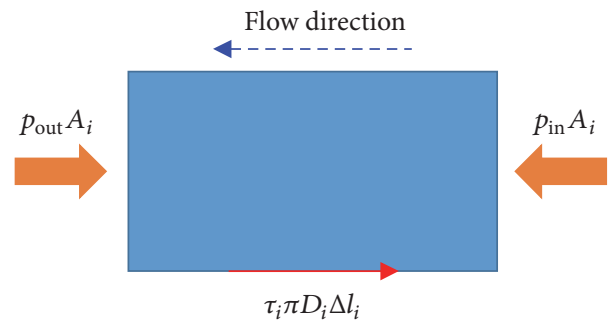

FIGURE 5: Sketch of microsegment in horizontal well.

increase of the flow rate. This will result in the change of the momentum of the fluid which leads to the acceleration pressure drop:

$$
\Delta p_{\text {acce }}=\rho_{i}\left(v_{\text {out }}^{2}-v_{\text {in }}^{2}\right) .
$$

Dimensionless form of the pressure drop along the well bore is given by (see Appendix for further details):

$$
\begin{aligned}
p_{D, i}- & p_{D, i+1} \\
= & \frac{2 \pi k h Q}{\mu A^{2}}\left(q_{p D, j}^{2}-q_{p D, j+1}^{2}-\frac{f_{j} \Delta l_{j}}{2 D} q_{p D, j}^{2}\right) .
\end{aligned}
$$

2.1.5. Coupling Relationship. Due to the pressure continuity at the center of each fracture, the pressure response obtained from the reservoir flow should be consistent with the fracture flow. Therefore, we have

$$
p_{j c D 1}=p_{j c D 2} .
$$

$p_{j c D 1}$ and $p_{j c D 2}$ are given by (7) and (9), respectively. The mass balance is applied to both the intersection nodes between fractures and the intersection nodes of fractures and wellbore (Figure 6). Therefore, for each node, the inflow of fluid must be equal to the outflow of the fluid,

$$
q_{\text {in }, D}=q_{\text {out }, D} .
$$

For the intersection nodes of fractures and wellbore, the inflow and outflow are taken into account between the fractures and between the fractures and the wellbore pipe.

2.2. Computational Approach. From (17), we obtain $n_{v}$ equations at the nodes for mass balance, $n_{p}$ equations for pressure drop along the fractures, and $n_{p}$ equations for pressure continuity in the panel centers, resulting in $n_{v}+2 n_{p}$ nonlinear equations that need to be solved. Newton's method has been widely used to solve systems of equations because of its quick convergence. However, it requires the inverse of Hessian matrix at each iteration and the convergence may not be reached if the Hessian matrix is ill-conditioned or nonpositive definite. Therefore, we use Gauss-Newton method, which is an improved version of Newton's method for finding a minimum of a function [47]. The basic idea is to use the Taylor series expansion to approximate nonlinear regression model and correct the solution through iteration. This algorithm is robust and has a good convergence rate. The iteration equation of Gauss-Newton method can be expressed as

$$
x^{k+1}=x^{k}-\left[\nabla F\left(x^{k}\right)^{T} \nabla F\left(x^{k}\right)\right]^{-1} \nabla F\left(x^{k}\right)^{T} F\left(x^{k}\right) .
$$

Pressure at each node, flow rate inside the fracture, and fluxes along the fractures can be obtained through iteration. Thus, dimensionless pressure at any point in the reservoir can be calculated via (7). If the bottom-hole pressure is given, we can get the flow rate in the same way. The flow rate behavior in different conditions can be obtained consequently. 


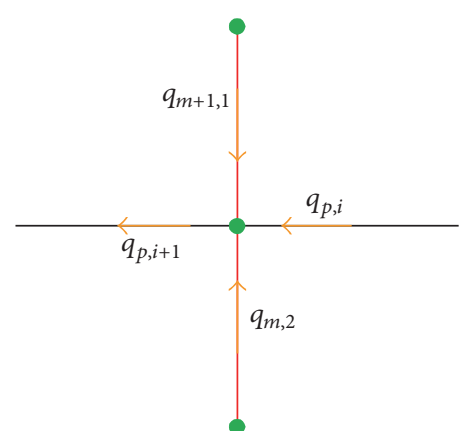

(a)

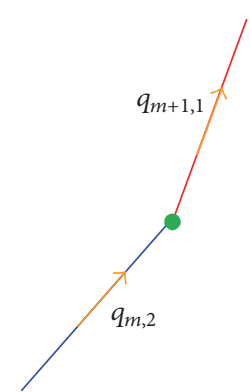

(b)

FIGURE 6: Sketch of mass balance at intersection nodes. (a) Intersection node between fractures and wellbore. (b) Intersection node between fractures. (Black line denotes wellbore, red lines represent hydraulic fracture, and blue line is natural fracture.)

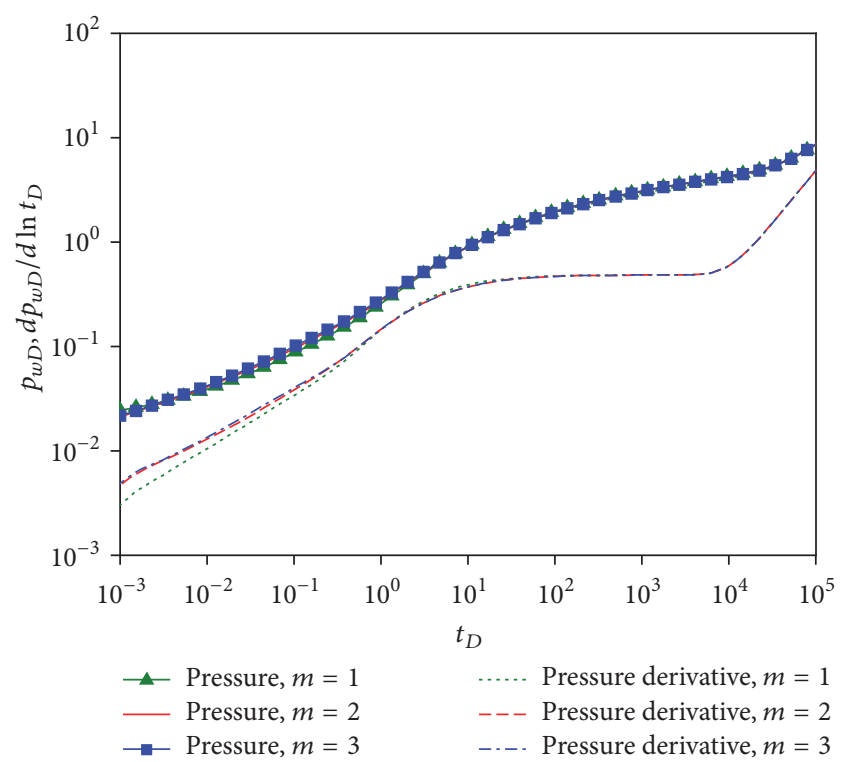

FIGURE 7: Effect of discretized number per fracture on the simulation result, $m$ is the number of discrete panels in each fracture.

2.3. Model Validation. While solving for the numerical solution, fractures are discretized into several panels and to ensure that we obtain correct numerical solution it is necessary to probe the grid independence with respect to the number of panels used. Figure 7 shows the grid independence analysis for a horizontal well with three transverse hydraulic fractures, where $m$ is the number of panels that a fracture is discretized into. We can conclude that the result we obtained from our model is independent of segment when $m$ is greater than 1 .

CMG, a commercial reservoir numerical simulator [48], was employed to validate our model. In this article, the IMEX module in CMG, which is a conventional three-phase blackoil simulator, is utilized to make the comparison. Interested readers may find the governing equations of this module from the textbooks on reservoir numerical simulation. The conventional Cartesian grids are employed and the total number of cells is $121 \times 121 \times 5$ and the basic parameters used

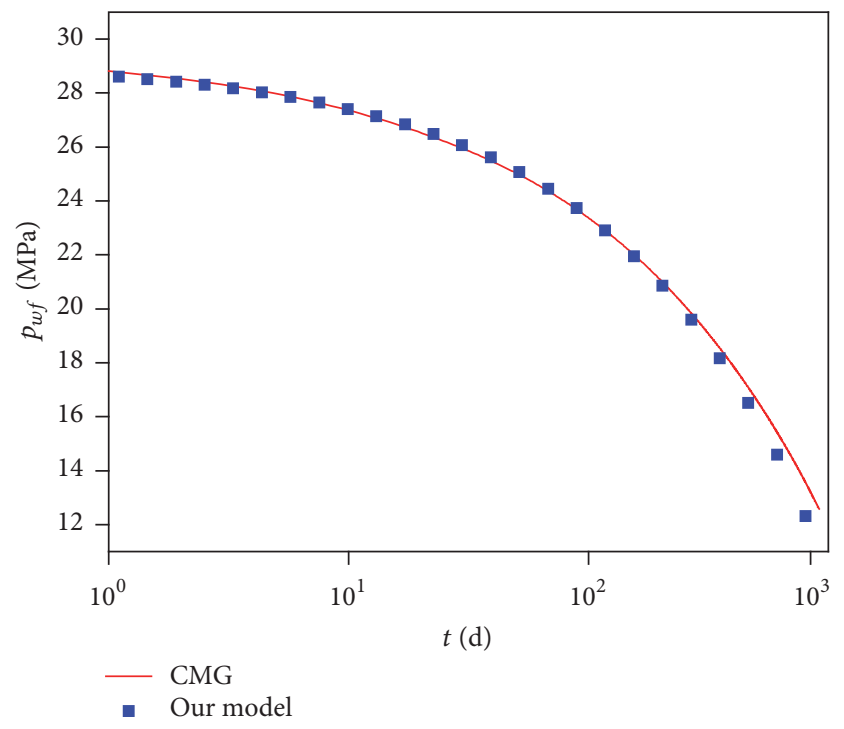

FIGURE 8: Bottom-hole pressure obtained using our proposed model and CMG.

in the validation are listed in Table 2 . The outer boundary of our simulation domain is impermeable. Meanwhile, to be consistent with the assumptions of our proposed model, we maintain the oil production rate constant in the simulation. Figure 8 compares the bottom-hole pressure obtained from CMG simulator and our model and it shows a good match during initial stage. Figure 9 shows the comparison of reservoir pressure from CMG with our model, and except for the pressures near fractures, we see a good match between the two. The reason for this slight difference around the fractures is because in CMG the fluid flows directly from the reservoir to the horizontal well, however, many studies $[27,49,50]$ have reported that the correct representation of fluid flow must consider intersection and activation of preexisting natural fractures with hydraulic fractures, which will create a complex fracture network. This representation of complex fracture network can be readily incorporated in our model; however, it is an extremely challenging task to do that in $\mathrm{CMG}$. 
$(\mathrm{MPa})$

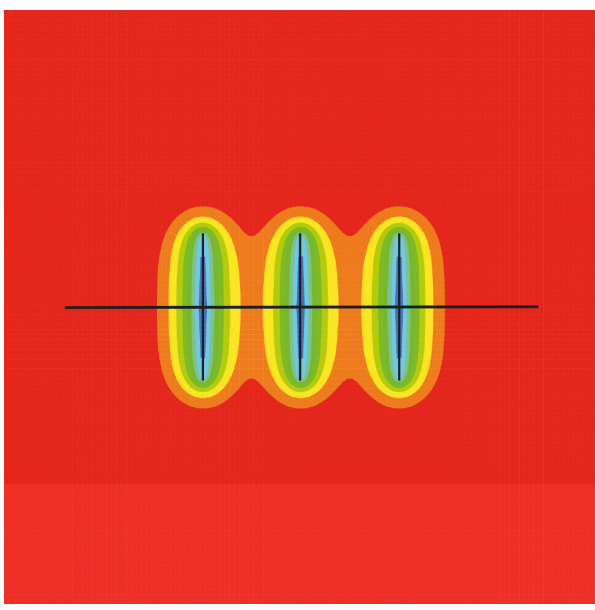

(a)

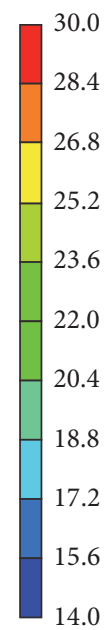

14.0

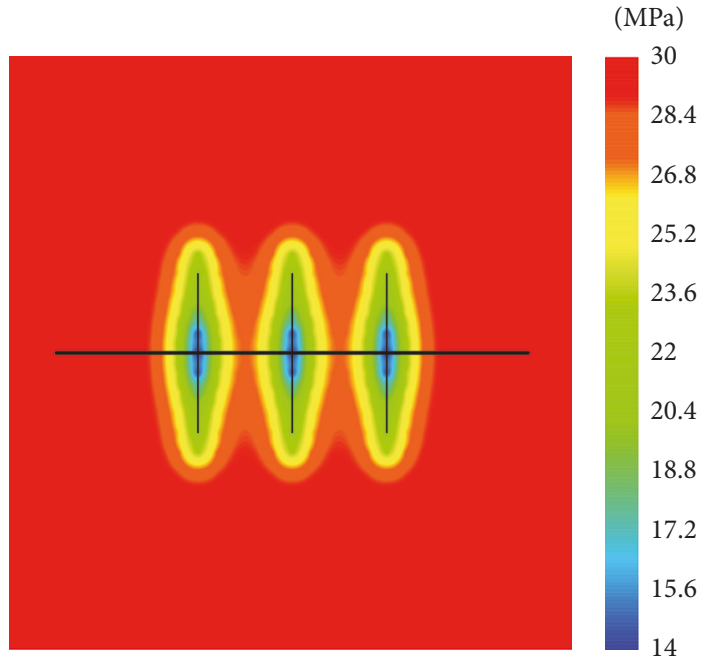

(b)

FIgURe 9: Pressure distribution of the reservoir. (a) CMG simulator. (b) Our model. The horizontal line represents the well.

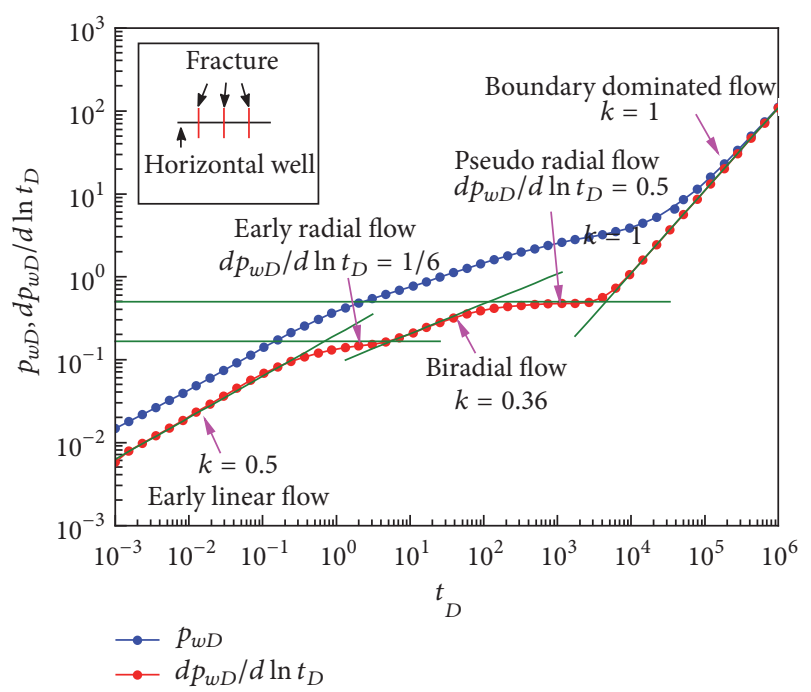

FIGURE 10: Pressure response of multistage fractured horizontal well (fracture number $n=3$, dimensionless fracture half-length $x_{f D}=1$, dimensionless fracture spacing $d_{D}=8$, and dimensionless reservoir length $\left.x_{e D}=240\right)$.

\section{Results and Discussions}

3.1. Flow Regime Analysis. The transient behavior can be shown by type curves, which is employed to obtain the characteristic of formation and the reservoir fluids and to figure out different flow regimes. Figure 10 shows the dimensionless well pressure and its derivative for a horizontal well with three fractures. The transient behavior can be divided into several flow periods.

(1) Linear Flow (Figure 11(a)). Fluid flows linearly from the reservoir to the fracture and each fracture behaves independently. Both the slope of dimensionless pressure and derivative is $1 / 2$ in this stage.
TABLE 2: Basic parameters for model validation.

\begin{tabular}{lc}
\hline Properties & Value \\
\hline Reservoir permeability $k, \mu \mathrm{m}^{2}$ & $1 \times 10^{-4}$ \\
Reservoir porosity, $\phi$ & $10 \%$ \\
Reservoir length, $x_{e}, \mathrm{~m}$ & 600 \\
Formation thickness, $h, \mathrm{~m}$ & 20 \\
Total compressibility, $C_{t}, \mathrm{MPa}^{-1}$ & $4 \times 10^{-3}$ \\
Initial pressure, $p_{i}, \mathrm{MPa}$ & 30 \\
Fluid viscosity, $\mu, \mathrm{mPa} \cdot \mathrm{s}$ & 20 \\
Fluid density, $\rho, \mathrm{kg} / \mathrm{m}^{3}$ & 900 \\
Fracture conductivity, $C_{d f}, \mu \mathrm{m}^{2} \cdot \mathrm{m}$ & 0.5 \\
Fracture half-length, $x_{f}, \mathrm{~m}$ & 75 \\
Fracture spacing, $d, \mathrm{~m}$ & 100 \\
Production rate, $Q, \mathrm{t} / \mathrm{d}$ & 4.32 \\
\hline
\end{tabular}

(2) Early Radial Flow (Figure 11(b)). An early radial flow occurs around each fracture after the linear flow. This period mainly depends on the fracture length and fracture spacing. Besides, in this period, fractures still behave independently. The characteristic of this stage is a horizontal line of $1 /(2 N)$ in pressure derivative curve ( $N$ is the fracture stage). We can figure out that the value of the horizontal line plateau is $1 / 6$.

(3) Biradial Flow (Figure 11(c)). Fractures interact with each other and flow becomes elliptical to the wellbore. The slope of pressure derivative is 0.36 .

(4) Pseudo Radial Flow (Figure 11(d)). Fluid flows to the fracture-well system appear to be radial and flow across the outermost elements plays important part. The pressure derivative curve demonstrates a horizontal line of 0.5 . 


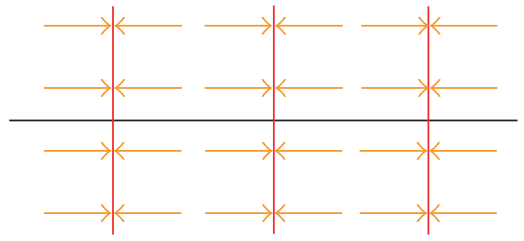

(a)

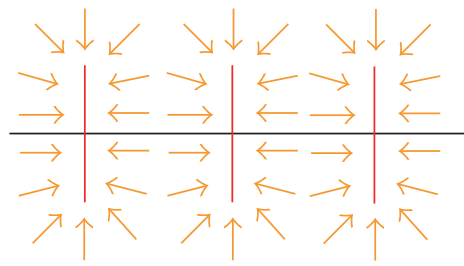

(b)

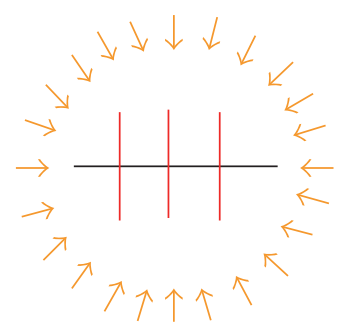

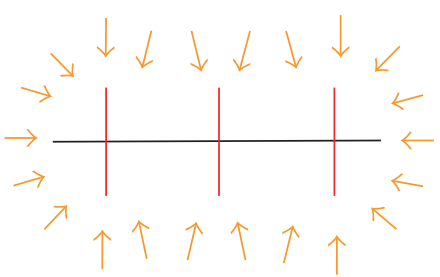

(c)

(d)

FIGURE 11: Flow regimes for a multistaged fractured horizontal well: (a) linear flow; (b) early radial flow, (c) biradial flow, and (d) pseudo radial flow.

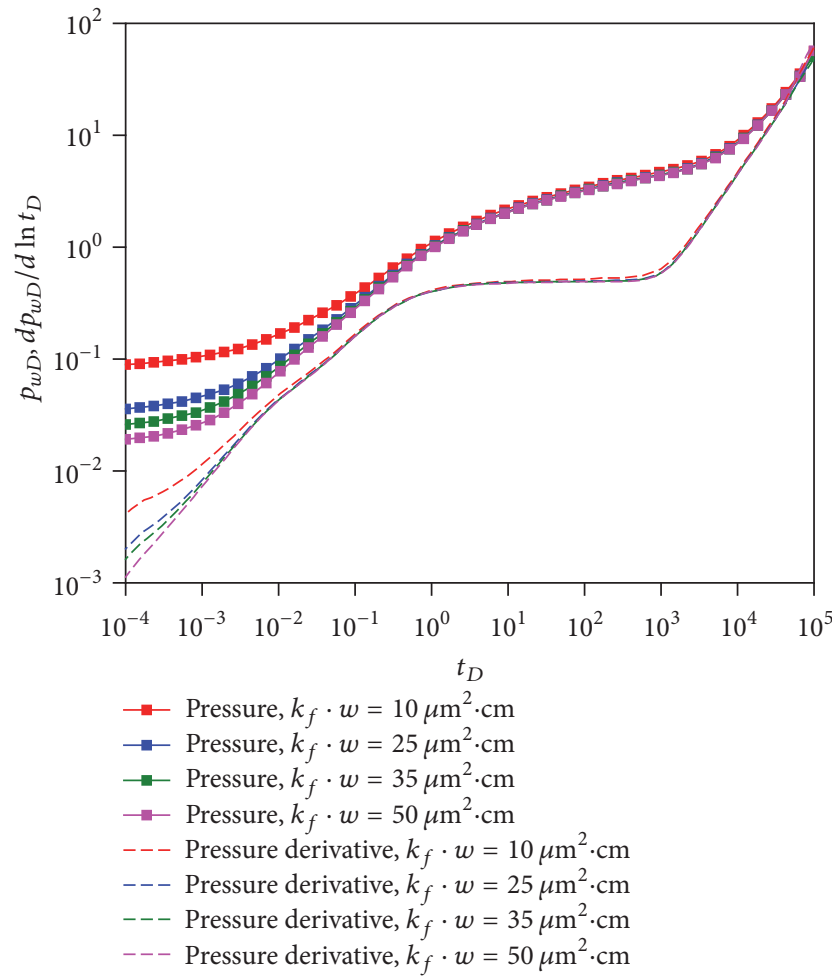

(a)

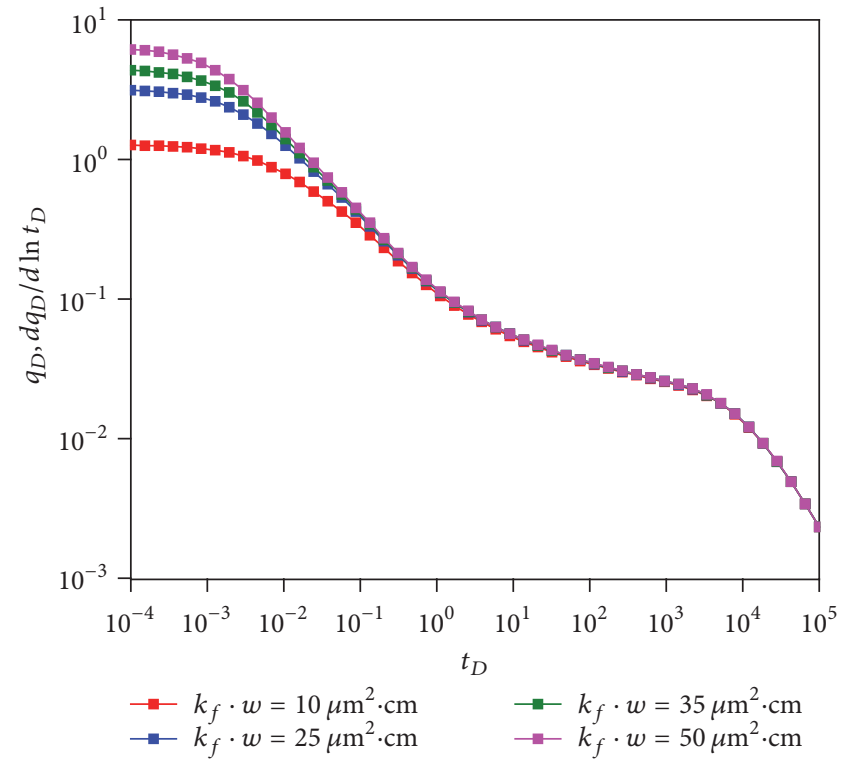

(b)

FIGURE 12: Effect of initial fracture conductivity on pressure and rate behavior (fracture number $n=2$, dimensionless fracture half-length $x_{f D}=1$, dimensionless fracture spacing $d_{D}=0.67$, and dimensionless reservoir length $x_{e D}=120$ ). (a) Pressure and derivative curve. (b) Dimensionless production rate.

(5) Boundary Dominated Flow. In the closed system, the flow will reach pseudo-steady state. The pressure curve and derivate tend to merge and the slope equals 1 .

3.2. Effect of Initial Fracture Conductivity. Figure 12 illustrates the effect of initial conductivity on the pressure transient response and production rate. This figure shows that increasing hydraulic fracture conductivity results in an increase in well productivity; however, the incremental benefit decreases as the fracture conductivity increases. Figure 12 also shows that variations in the dimensionless pressure and the production rate tend to disappear as the flow regime approaches 


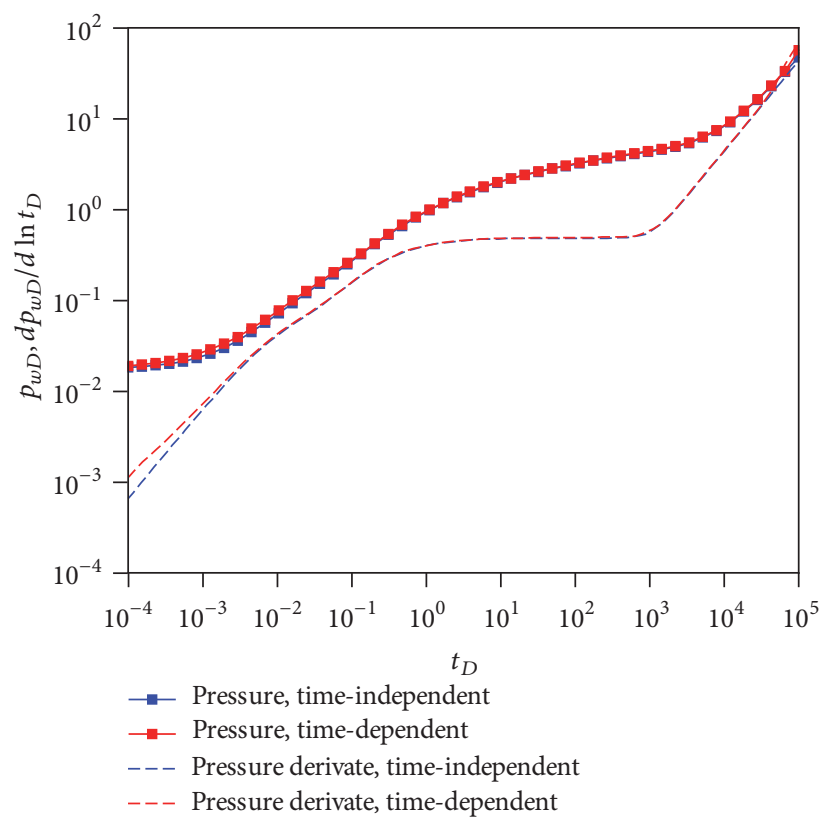

(a)

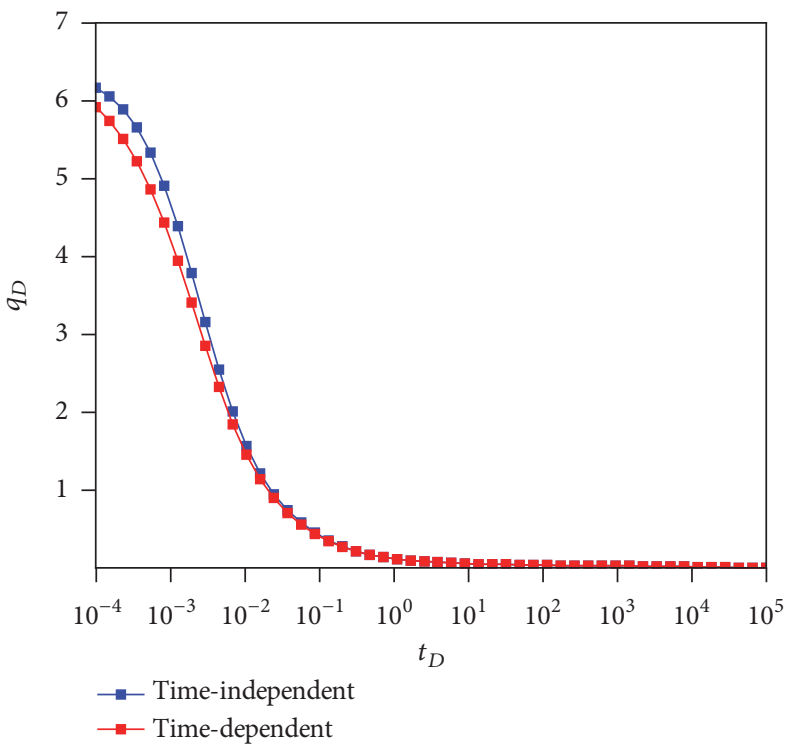

(b)

FIGURE 13: Effect of time-dependent fracture conductivity on pressure and rate behavior (fracture number $n=2$, dimensionless fracture half-length $x_{f D}=1$, dimensionless fracture spacing $d_{D}=0.67$, dimensionless reservoir length $x_{e D}=120$, and decline coefficient $\beta=0.11$ ). (a) Dimensionless pressure and derivative curve. (b) Dimensionless production rate.

pseudo radial flow. The reason why the variations in these two parameters disappear is because the flow at late times is dominated by the outer reservoir, and therefore, the effect of fracture conductivity will be extremely small. Therefore, to utilize the potential of the hydraulic fractures, we must delay the occurrence of pseudo radial flow and that can be done by optimal well placement.

Although it is well documented that the fracture conductivity decreases rapidly at first and tends to converge asymptotically [31-34, 37], previous studies always assumed that hydraulic fractures do not vary with time. Below, we analyze the difference between time-independent and time-dependent fractures. As discussed earlier, the conductivity, and hence the productivity of the horizontal well, decreases with time. Therefore, the pressure response of the well is larger than the time-independent situation, as suggested by Figure 13(a). The flow rate of a horizontal well with time-independent conductivity fractures exceeds that with time-dependent conductivity fractures in the initial stage (Figure 13(b)), and that could be attributed to the dominant role of fractures. During late times of production, the fluid flow in the outer reservoir becomes dominant and negligible difference can be observed between time-dependent and time-independent cases. Therefore, for the optimal exploitation of an unconventional reservoir it is necessary to maintain the fracture conductivity, especially in the initial stage of the production.

Figure 14 shows the effect of decline coefficient on the production performance of the horizontal well, where a larger decline coefficient results in smaller production rate and if the decline coefficient is too large the fracture permeability tends to quickly approach the formation permeability, which results in sharp decline in the production rate.

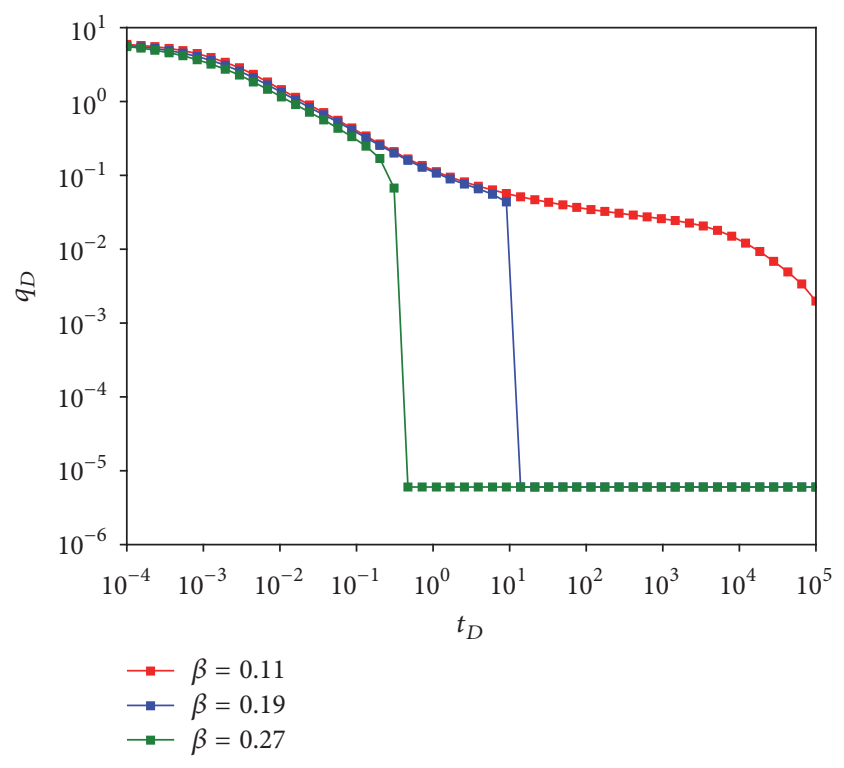

FIGURE 14: Effect of decline coefficient on the production performance of the horizontal well (fracture number $n=2$, dimensionless fracture half-length $x_{f D}=1$, dimensionless fracture spacing $d_{D}=$ 0.67 , and dimensionless reservoir length $x_{e D}=120$ ).

3.3. Effect of Fracture Distribution. The pressure difference created during hydraulic fracturing allows the proppants to stay in the fractures away from the horizontal well heel [51], and as a result, the fracture conductivities are different that may further have an impact on the pressure behavior. Two scenarios of even and uneven proppant distribution can be 


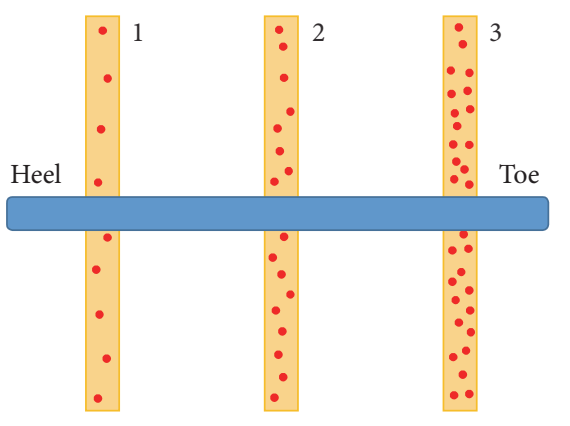

(a)

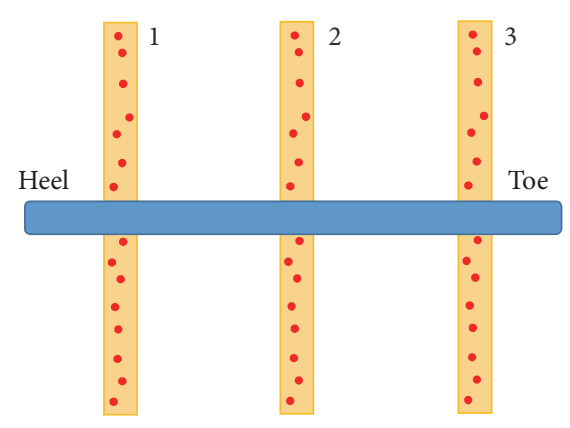

(b)

FIGURE 15: Sketch of proppant distribution in different fracture: (a) uneven distribution; (b) even distribution.

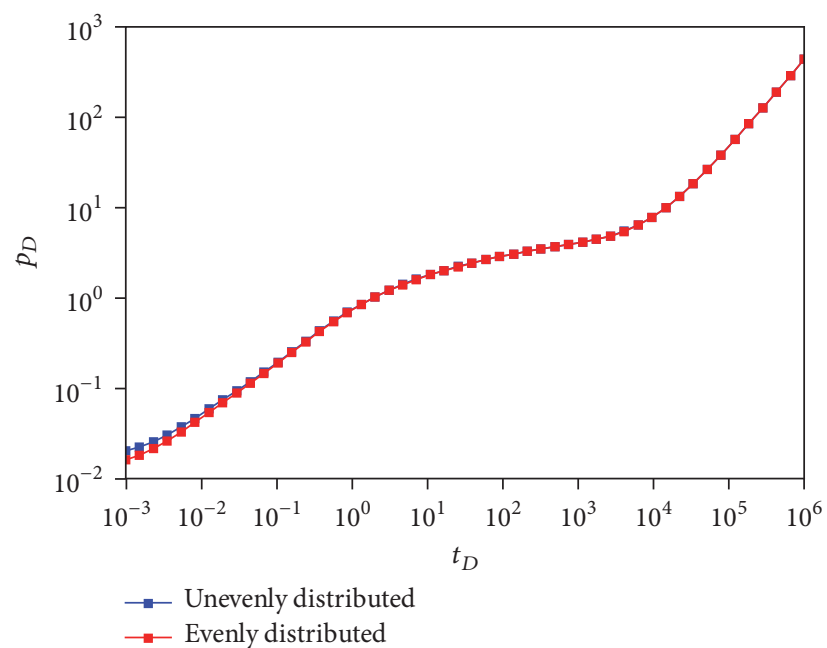

(a)

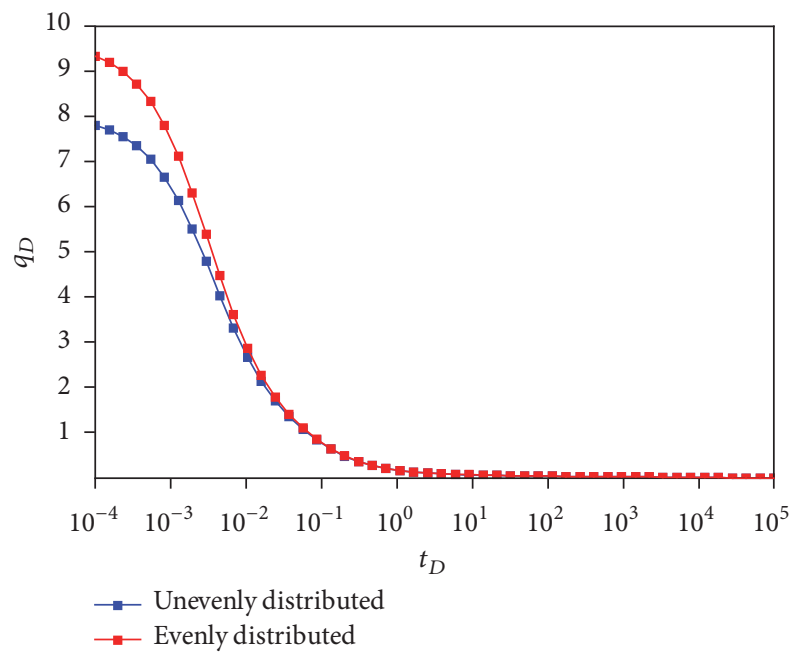

(b)

FIGURE 16: Effect of unevenly distributed fracture conductivity on the pressure and production behavior (fracture number $n=3$, dimensionless fracture half-length $x_{f D}=1$, dimensionless fracture spacing $d_{D}=0.67$, dimensionless reservoir length $x_{e D}=120$. The conductivity of evenly distributed fracture is $0.375 \mu \mathrm{m}^{2} \cdot \mathrm{m}$; for unevenly distributed fracture, the conductivities are $0.25 \mu \mathrm{m}^{2} \cdot \mathrm{m}, 0.375 \mu \mathrm{m}^{2} \cdot \mathrm{m}$, and $0.5 \mu \mathrm{m}^{2} \cdot \mathrm{m}$.). (a) Dimensionless pressure curve. (b) Dimensionless production rate curve.

seen as schematics in Figures 15(a) and 15(b), respectively, which are used to study the effect of proppant distribution.

For unevenly distributed fractures, the fracture nearest to the well toe has the largest conductivity, whereas the conductivity of the intermediate fracture equals that of the evenly distributed fractures.

Figure 16(a) shows the dimensionless pressure drop of a horizontal well (at constant production rate multistage fractured well) with evenly distributed and unevenly distributed fractures. The pressure response with unevenly distributed proppants is slightly larger than that with evenly distributed proppants at initial period but the gap disappears after that. Result of Figure 16(b) suggests that horizontal well with evenly distributed proppants produces with higher rate initially than with unevenly distributed proppants. Therefore, these two results indicate that well with evenly distributed proppants performs better than that with unevenly distributed proppants.

Figure 17 shows the dimensionless flux rate of three fractures that have evenly and unevenly distributed proppants.
When the fracture conductivities (or proppant distribution) are evenly distributed, the dimensionless flux rate of Fractures 1 and 3 increases with time, but the flux rate of Fracture 2 decreases sharply with time. At the initial stage, each fracture behaves independently; however, with time the fractures begin to interfere with each other and the flux rate of Fractures 1 and 3 tends to increase, whereas owing to the symmetry, the flux rate of intermediate fracture, Fracture 2, is hindered. If the fracture conductivities are unevenly distributed, the flux rate of the third fracture will first decrease and then increase with the time. However, production rate of the first fracture increases steadily with time and it crosses the conductivity of the second fracture at some point.

3.4. Effect of Fracture Geometry. In hydraulic fracturing, the existent propped fractures result in the redistribution of local earth stresses. Moreover, microseismic measurements have proved that there is mechanical-stress interference between multiple transverse fractures. The stress-shadow effect can restrict the growth of the fracture in the middle section while 


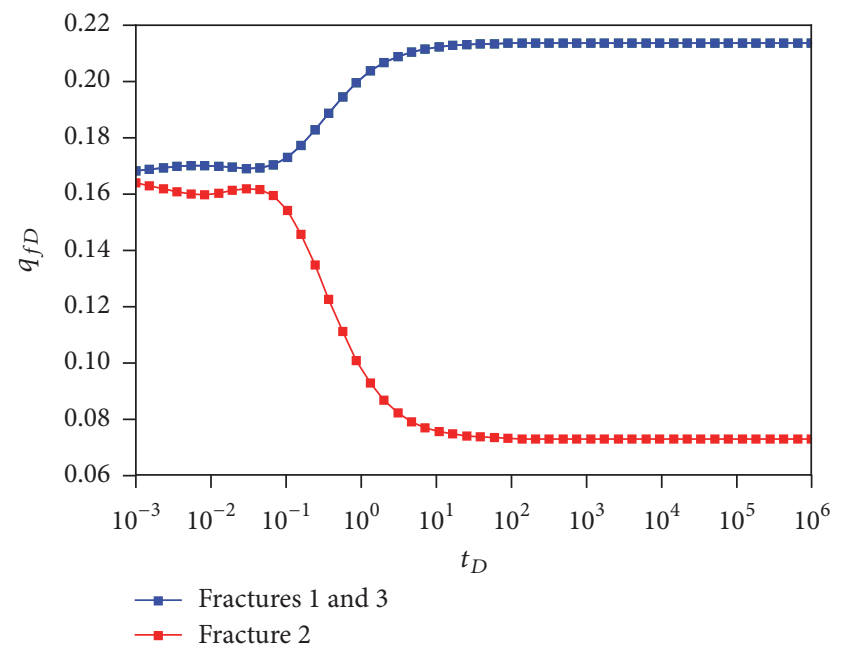

(a)

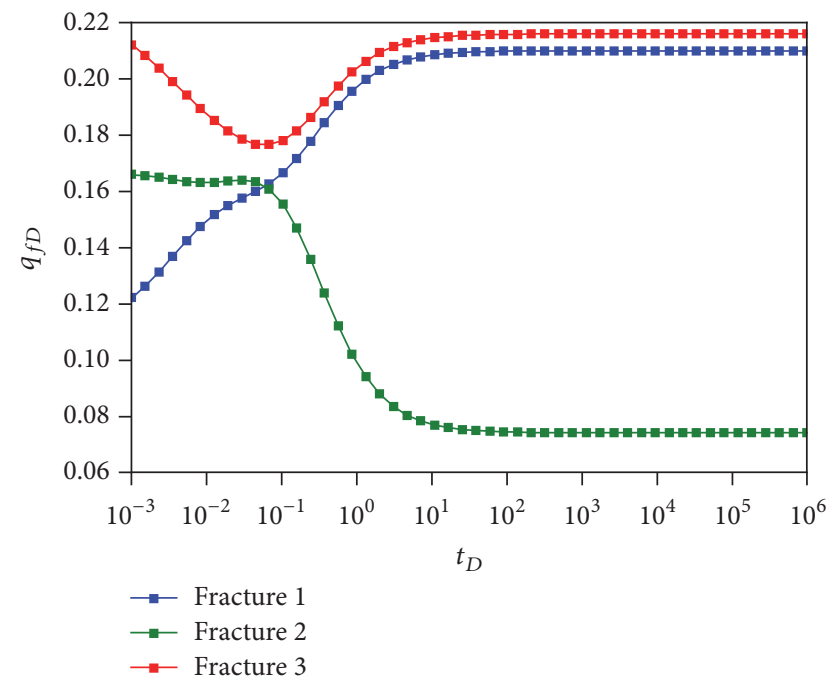

(b)

FIGURE 17: Dimensionless flux rate of each fracture. (a) Fracture conductivity evenly distributed. (b) Fracture conductivity unevenly distributed.

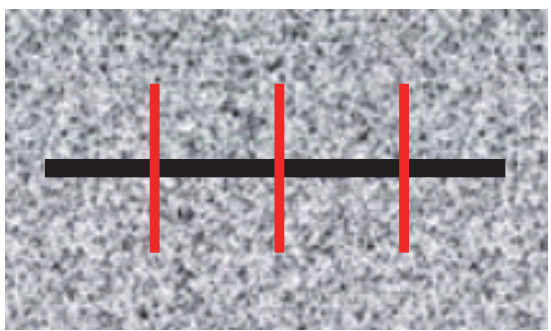

(a)

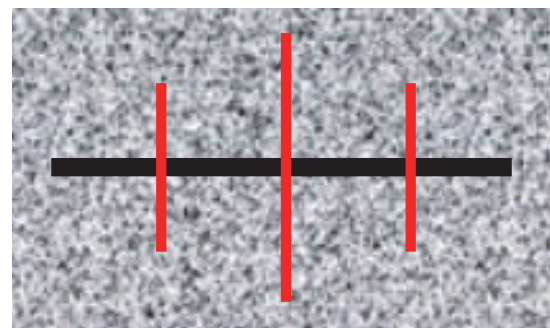

(b)

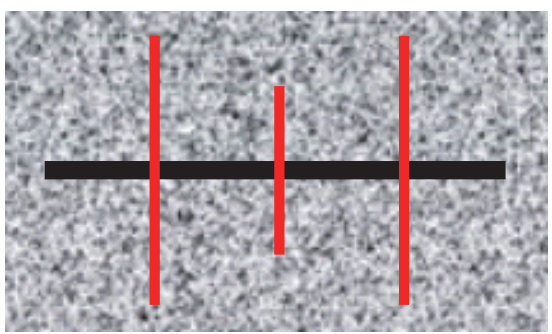

(c)

FiguRE 18: Sketch of different fracture geometries. (a) Equilong type. (b) Spindle-shaped type. (c) Dumbbell-shaped type.

promoting the growth of the fractures at the heel or the toe $[49,52]$; therefore, different fracture geometry may exist in the reservoir. Three geometries shown in Figure 18, equilong type, spindle-shaped type, and dumbbell-shaped type, are studied.

Figure 19 shows the dimensionless flux rate of three fractures from three fracture geometries of Figure 18, respectively. For spindle-shaped geometry, the flux rate of the first and third fracture will first decrease and then slightly increase before levelling off at long time (Figure 19(b)). However, the flux of the second fracture always remains smaller than the other two fractures, although it has a larger fracture length. Figure 19(c) shows that, for dumbbell-shaped geometry, the flux rate of fractures near the heel and toe will slightly increase with time, whereas the flux of the intermediate fracture will sharply decrease with time. From these results it is evident that no matter what the fracture geometry is, the flux of the intermediate fracture always decreases with time. Figure 20 suggests that if the bottom-hole pressure is constant, the production rate of equilong fracture type is higher than the others because it has the longest effective interference fracture length. Apparently, this is the reason why equilong fracture type is usually preferred over other fracture geometries.
3.5. Effect of Horizontal Wellbore Pressure Drop. Many previous studies considered the horizontal wellbore as an infinite wellbore; however, it has been shown that wellbore pressure drop exists in the production [53, 54]. We investigated the effect of horizontal wellbore pressure drop on pressure behavior as shown in Figure 21, which shows that the effect of considering wellbore pressure drop is negligible. This observation can be explained by the low permeability and low flow rate in ultratight reservoir. Therefore, we conclude that the horizontal wellbore pressure drop can be neglected in ultratight reservoir.

3.6. Complex Fracture Network. It is inappropriate to simulate the production with biwing fracture when the characteristic of complex fracture network is evident [55-57]. Figure 22 shows the schematic of a complex fracture network, the red lines represent the hydraulic fractures, the blue lines are natural fractures, and black line denotes horizontal well. Parameters of the reservoir, fluid, and the fractures are shown in Table 3. Figure 23 shows the pressure distribution of the complex fracture network at different times. With increasing time, the area that contributes to production as well as the elastic production in a specific volume increases. 


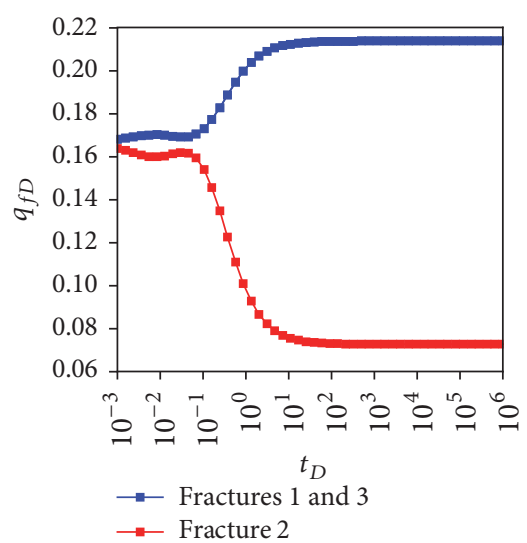

(a)

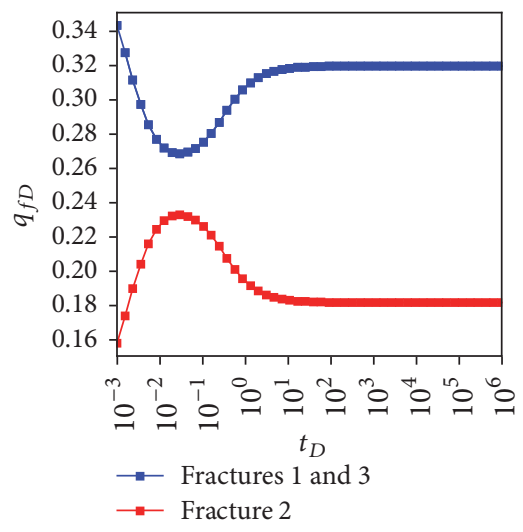

(b)

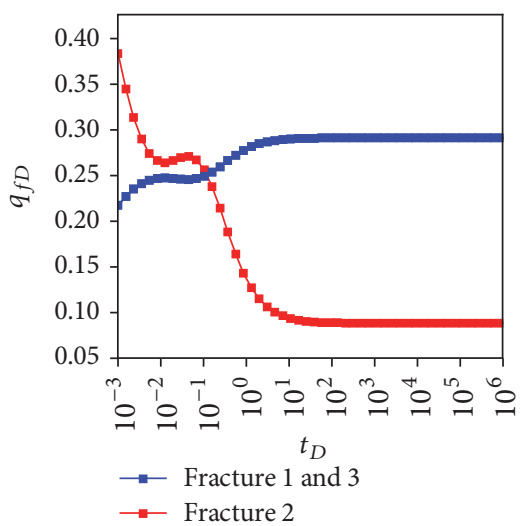

(c)

Figure 19: Dimensionless flux rate of each fracture. (a) Equilong type, $x_{f 1}=x_{f 2}=x_{f 3}=100 \mathrm{~m}$. (b) Spindle-shaped type, $x_{f 1}=75 \mathrm{~m}$, $x_{f 2}=150 \mathrm{~m}$, and $x_{f 3}=75 \mathrm{~m}$. (c) Dumbbell-shaped type, $x_{f 1}=120 \mathrm{~m}, x_{f 2}=60 \mathrm{~m}$, and $x_{f 3}=120 \mathrm{~m}$.

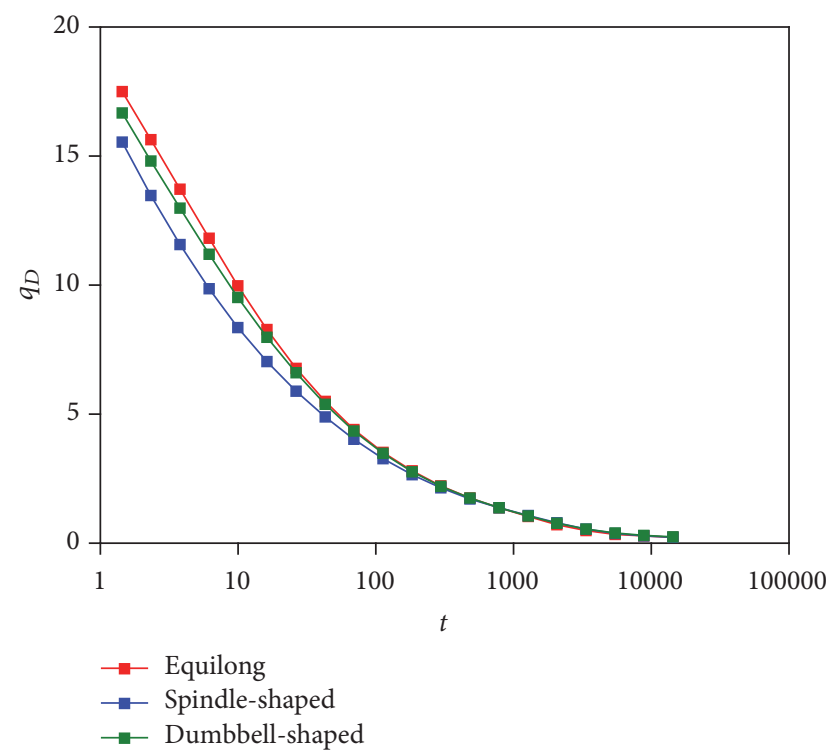

Figure 20: Dimensionless production rate for different fracture configurations.

\section{Field Example}

Well J172-H is a multistage fractured horizontal well in Jimsar sag, which is a typical tight oil region located in the southeast of the Junggar Basin of China. Tight oil in the sag is mainly in Permian Lucaogou Formation, which is divided into the first member and the second member from bottom to top (Figure 24). Sweet spots are developed in the lower parts of both members, that is, the upper sweet spot and the lower sweet spot. J172-H is placed in the upper sweet spot, and the reservoir is characterized by alternating layers of fine dolarenite, dolomitic siltstone, and fine dolomitic mudstone in the vertical direction [58]. The interpretation of nuclear magnetic log shows that the porosity of the upper sweet spot lies between 0.061 and 0.258 , with an average of 0.101 , whereas
TABLE 3: Basic parameters for complex fracture network case.

\begin{tabular}{lc}
\hline Properties & Value \\
\hline Reservoir permeability, $k, \mu \mathrm{m}^{2}$ & $1 \times 10^{-4}$ \\
Reservoir porosity, $\phi$ & $10 \%$ \\
Reservoir length, $x_{e}, \mathrm{~m}$ & 600 \\
Formation thickness, $h, \mathrm{~m}$ & 20 \\
Total compressibility, $C_{t}, \mathrm{MPa}^{-1}$ & $2.76 \times 10^{-3}$ \\
Initial pressure, $p_{i}, \mathrm{MPa}$ & 30 \\
Fluid viscosity, $\mu, \mathrm{mPa} \cdot \mathrm{s}$ & 20 \\
Fluid density, $\rho, \mathrm{kg} / \mathrm{m}^{3}$ & 900 \\
Hydraulic fracture conductivity, $C_{d f}, \mu \mathrm{m}^{2} \cdot \mathrm{m}$ & 0.2 \\
Natural fracture conductivity, $C_{d n}, \mu \mathrm{m}^{2} \cdot \mathrm{m}$ & 0.04 \\
Production rate, $Q, \mathrm{t} / \mathrm{d}$ & 1.92 \\
\hline
\end{tabular}

the permeability of the upper sweet spot is in the range of $0.001 \times 10^{-3} \mu \mathrm{m}^{2}$ to $0.284 \times 10^{-3} \mu \mathrm{m}^{2}$, with an average of $0.012 \times 10^{-3} \mu \mathrm{m}^{2}$. The permeability of over 90 percent of the samples is less than $0.1 \times 10^{-3} \mu \mathrm{m}^{2}$.

J172-H went into production in September of 2012, and during the initial stage the production rate of $\mathrm{J} 172-\mathrm{H}$ was approximately 15 times that of the adjacent vertical well. A build-up well test was conducted in May of 2013 and Figure 25 shows the pressure and pressure derivative data of that buildup test, which was conducted for a short period. Thus, it can be concluded that the data shown in Figure 25 comes from very beginning of the build-up test.

Due to the short test and ultralow reservoir permeability, some characteristic responses in the middle and late time period, corresponding to the biradial flow and boundary dominated flow regimes featured by the slope of 0.36 and 1 in the pressure derivative curve, cannot be found from the well test data. In the regimes of wellbore storage and early linear flow, the slopes of pressure derivative curves are equal to 1 and 0.5 , respectively. We matched the curves with straight lines of slope 1 and 0.5 and identified the flow regime from the data as wellbore storage period and linear flow period. Note 


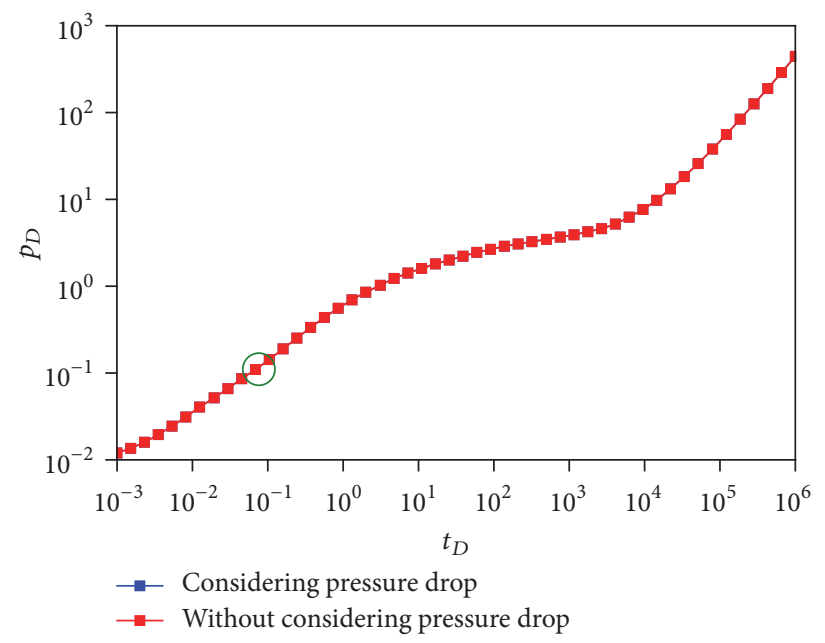

(a)

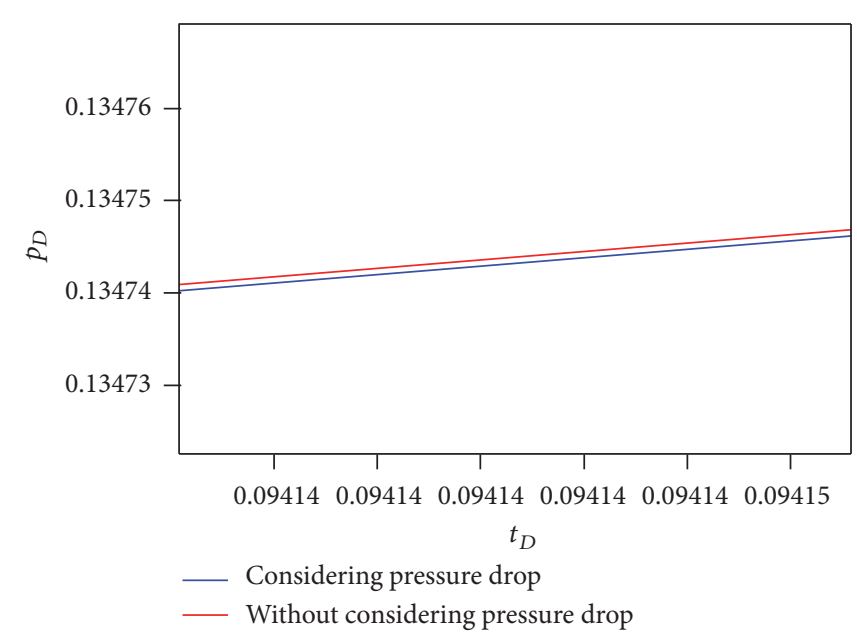

(b)

FIGURE 21: Effect of horizontal wellbore pressure drop on pressure behavior. (a) Pressure curve of multistage fractured horizontal well. (b) An enlarged view of pressure curve within green circle.

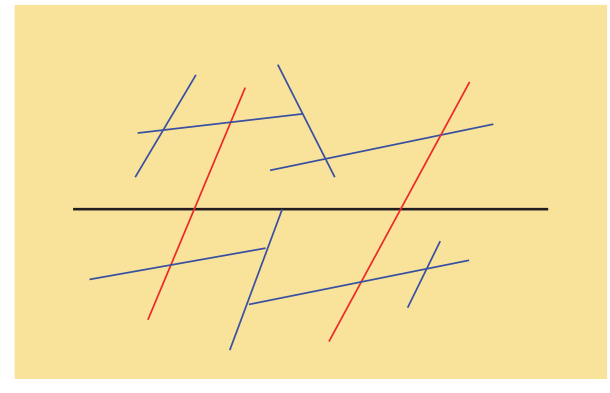

FIGURE 22: Schematic of a complex fracture network. The black, red, and blue lines represent the wellbore, hydraulic fractures, and natural fractures, respectively.

that the effect of wellbore storage is not taken into account in this study, because our model is proposed on the basis of Green's function in real domain and it is difficult to obtain the derivative of pressure with respect to time in the inner boundary condition. However, the wellbore storage effect can be accounted for by transforming the equations from real domain to the Laplace domain by using the following equation:

$$
\bar{p}_{w D \text {,storage,skin }}=\frac{s \bar{p}_{w D}+S}{s+C_{D} s^{2}\left(s \bar{p}_{w D}+S\right)},
$$

where $\bar{p}_{w D \text {,storage,skin }}$ stands for the dimensionless pressure including wellbore storage and skin effects (in Laplace space), $\bar{p}_{w D}$ is the dimensionless pressure without these effects (in Laplace space), $s$ is the Laplace variable, and $C_{D}$ and $S$ are the wellbore storage coefficient and skin factor, respectively. This is the subject of future studies. Therefore, data from the linear flow period is employed in our analysis. A physical experiment was conducted to estimate the decline coefficient of hydraulic fractures, and the resulting value is 0.106 . Figure 26 shows the match for linear flow regime, from
TABLE 4: Comparison between fitting parameter and the field data.

\begin{tabular}{lcc}
\hline Parameter & Our model & Field data \\
\hline Fracture half-length, $\mathrm{m}$ & 148 & $110 \sim 230$ \\
Fracture spacing, $\mathrm{m}$ & 81 & 78.5 (in average) \\
Formation permeability, $10^{-3} \mu \mathrm{m}^{2}$ & 0.0107 & $0.001 \sim 0.284$ \\
\hline
\end{tabular}

which we estimate the fracture and reservoir parameters. In Table 4, we compare the fitting parameters from our proposed model and the field data from microseismic monitoring. Our estimated average half-length of these fractures approximates to $148 \mathrm{~m}$, which lies in the range of $110-230 \mathrm{~m}$. The fracture spacing obtained from our match, $81 \mathrm{~m}$, approximates to the average value from microseismic map. Because the reservoir heterogeneity is not taken into account in our proposed model, we only get the mean permeability of the formation, which is fairly comparable to the well logging results.

\section{Conclusions}

A semianalytical model was proposed to analyze the pressure behavior of multistage fractured horizontal well in tight oil reservoirs. Factors that influence the pressure behavior of multistage fractured horizontal well were analyzed to provide a deep understanding of the pressure transient behavior. Following conclusions were reached.

(1) Higher hydraulic fracture conductivity will result in an increase in well productivity. Therefore, hydraulic fracture conductivities should be optimized according to the well performance and investment.

(2) The stimulated region has more significant importance on the transient pressure and rate behavior than the outer reservoir region. In order to make use of the hydraulic fractures, the existence of pseudo radial flow must be delayed through optimal well placement. 


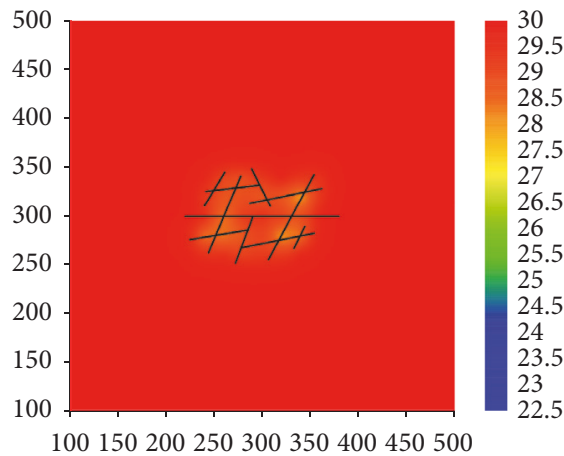

(a)

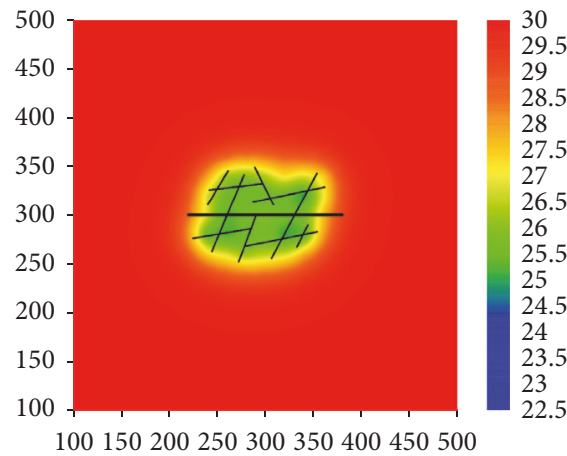

(b)

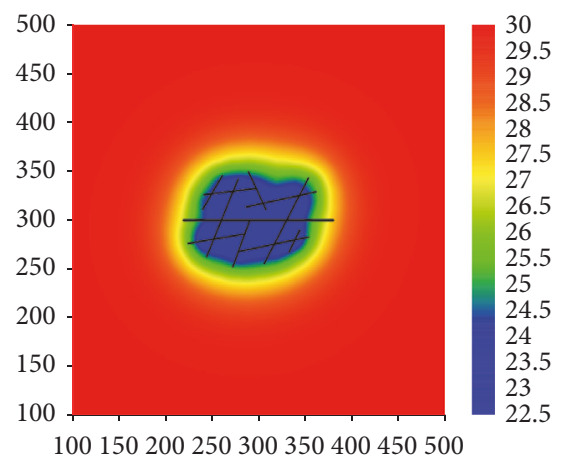

(c)

Figure 23: Pressure distribution of complex fracture network at different production time. (a) $t=100 \mathrm{~d}$, (b) $t=500 \mathrm{~d}$, and (c) $t=1000 \mathrm{~d}$.
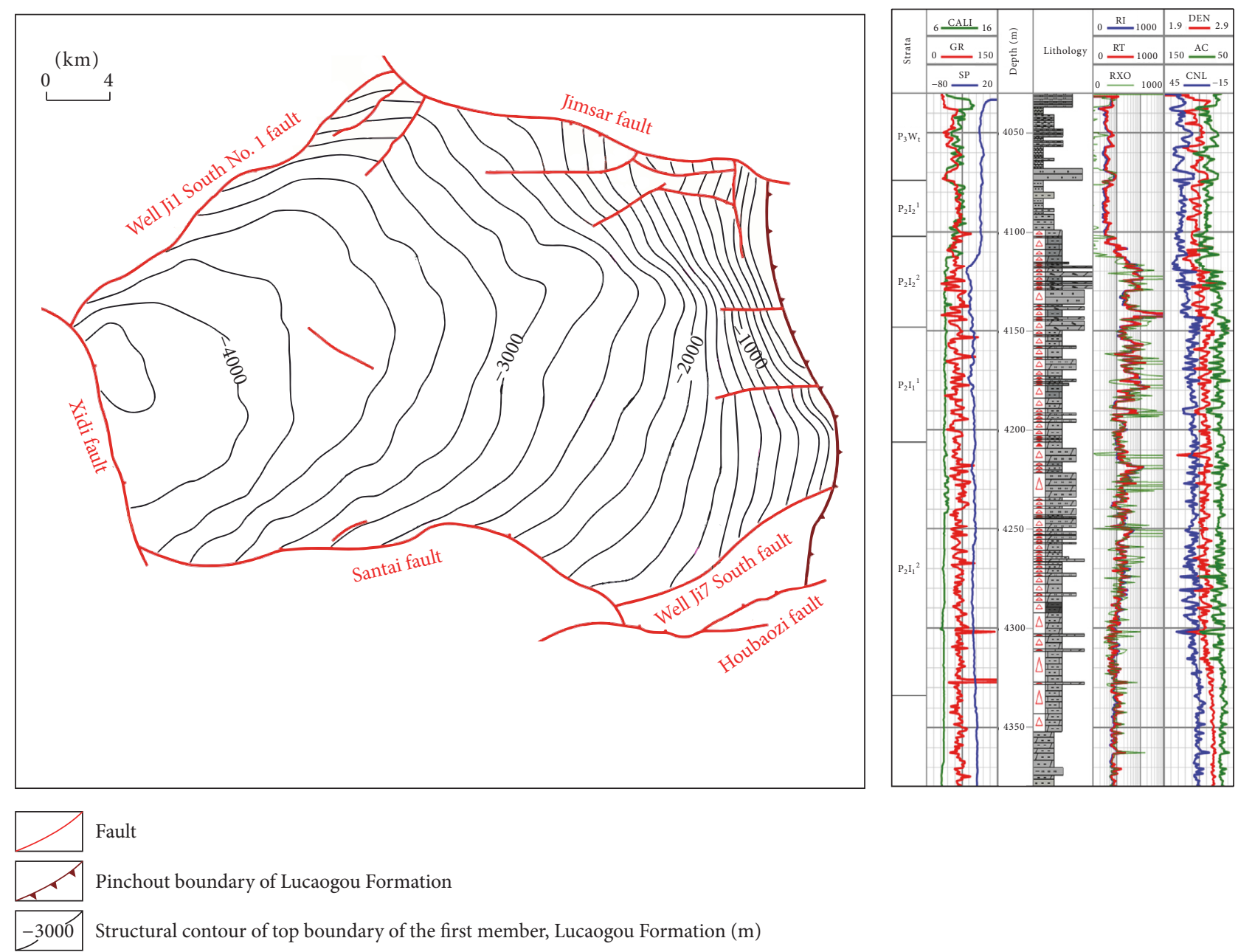

(a)

(b)

FIgURE 24: Tectonic location and comprehensive logging evaluation of Lucaogou Formation in Jimsar sag. 


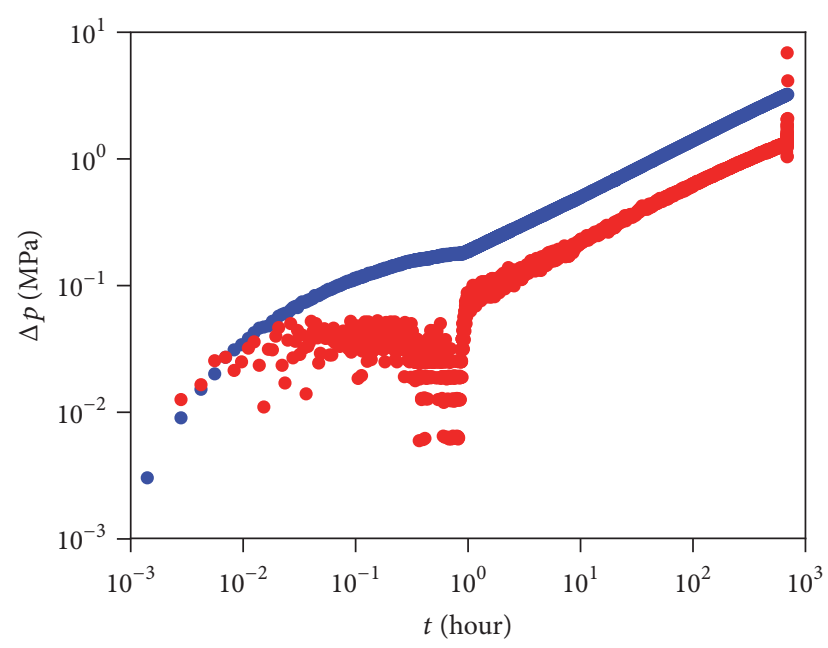

- Pressure

- Pressure derivative

FIGURE 25: Well build-up test data of J172-H.

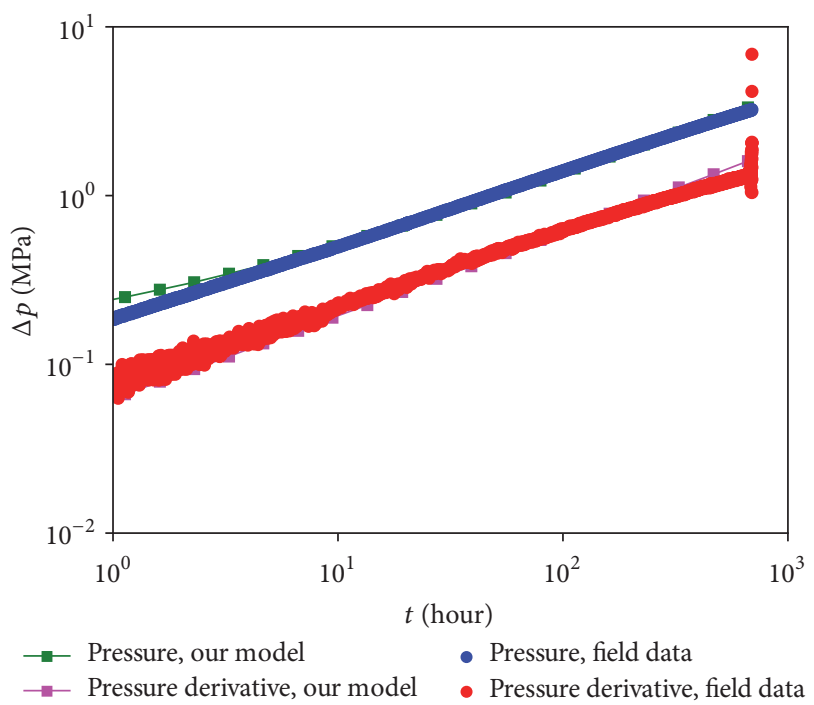

FIgURE 26: Curve match for linear flow.

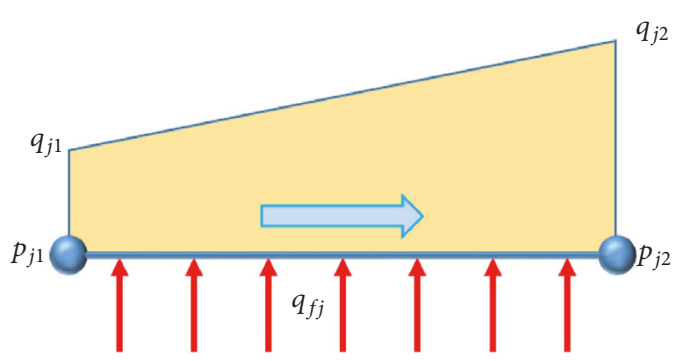

FIGURE 27: Fluid flow in panel $j$.

(3) The comparison among different factors suggests that fracture conductivity is the most important factor when exploiting the full potential of a horizontal well. The decline of fracture conductivity has a tremendous influence on the well performance. Therefore, the proppant selection should be given the first priority to maintain the fracture conductivity.
(4) The interference among fractures of equilong type is the strongest. This geometry is favorable for both fracture flux rate and total production rate.

(5) Due to the low permeability and flow rate of ultratight reservoir, the effect of wellbore pressure drop is negligible; therefore, the horizontal wellbore pressure drop can be ignored in ultratight reservoir.

\section{Appendix}

Here we provide the detailed derivation of equations that describe fluid flow in reservoir, fracture, and wellbore.

Reservoir Flow. For fractures rotated at any horizontal angle to the well, instantaneous point function can be obtained through the superposition of source function in three dimensions. Then the instantaneous plane function of the fracture panel can be calculated through the integration on the fracture panel. The infinite plane source function in slab reservoir with no-flow boundary is

$$
\begin{aligned}
& \mathrm{VII}(x)=\frac{1}{x_{e}}[1 \\
& \left.+2 \sum_{n=1}^{\infty} \exp \left(-\frac{n^{2} \pi^{2} \eta_{x} t}{x_{e}^{2}}\right) \cos n \pi \frac{x_{w}}{x_{e}} \cos \frac{n \pi x}{x_{e}}\right],
\end{aligned}
$$

where $x_{w}$ denotes the location of the plane source and $x$ is the value in $x$-direction of an arbitrary point in the reservoir. By applying Newman method, the instantaneous point function is described as

$$
\begin{aligned}
& S(x, y, z)=\mathrm{VII}(x) \mathrm{VII}(y) \mathrm{VII}(z)=\frac{1}{x_{e} y_{e} z_{e}}[1 \\
& \left.+2 \sum_{n=1}^{\infty} \exp \left(-\frac{n^{2} \pi^{2} \eta_{x} t}{x_{e}^{2}}\right) \cos n \pi \frac{x_{w}}{x_{e}} \cos \frac{n \pi x}{x_{e}}\right] \\
& .[1 \\
& \left.+2 \sum_{n=1}^{\infty} \exp \left(-\frac{n^{2} \pi^{2} \eta_{y} t}{y_{e}^{2}}\right) \cos n \pi \frac{y_{w}}{y_{e}} \cos \frac{n \pi y}{y_{e}}\right] \\
& .\left[1+2 \sum_{n=1}^{\infty} \exp \left(-\frac{n^{2} \pi^{2} \eta_{z} t}{z_{e}^{2}}\right) \cos n \pi \frac{z_{w}}{z_{e}} \cos \frac{n \pi z}{z_{e}}\right] .
\end{aligned}
$$

Through integration, the instantaneous plane function of the fracture panel can be expressed by

$$
\begin{aligned}
& S_{j}(x, y, z)=\frac{1}{x_{e} y_{e} z_{e}} \int_{x_{j 1}}^{x_{j 2}} \int_{0}^{z_{e}}[1 \\
& \left.\quad+2 \sum_{n=1}^{\infty} \exp \left(-\frac{n^{2} \pi^{2} \eta_{x} t}{x_{e}^{2}}\right) \cos n \pi \frac{x^{\prime}}{x_{e}} \cos n \pi \frac{x}{x_{e}}\right]
\end{aligned}
$$




$$
\begin{aligned}
& \cdot\left[1+2 \sum_{n=1}^{\infty} \exp \left(-\frac{n^{2} \pi^{2} \eta_{y} t}{y_{e}^{2}}\right)\right. \\
& \left.\cdot \cos n \pi \frac{y_{j 1}+x^{\prime} \tan \theta_{j}}{y_{e}} \cos n \pi \frac{y}{y_{e}}\right] \cdot[1 \\
& +2 \sum_{n=1}^{\infty} \exp \left(-\frac{n^{2} \pi^{2} \eta_{z} t}{z_{e}^{2}}\right) \cos n \pi \frac{z^{\prime}}{z_{e}} \\
& \left.\cdot \cos \frac{n \pi z}{z_{e}}\right] d x^{\prime} d z^{\prime} .
\end{aligned}
$$

Fractures perpendicular to the horizontal well can be treated as a special case of the above situation. Complex double integration is no longer needed in calculating the source function of the fracture panels. The instantaneous plane function of the fracture panel can be directly obtained through the superposition of infinite slab source function and infinite plane source function in slab reservoir with no-flow boundaries.

The infinite slab source function in slab reservoir with noflow boundary is

$$
\begin{aligned}
& \mathrm{X}(x)=\frac{x_{f}}{x_{e}}\left[1+\frac{4 x_{e}}{\pi x_{f}} \sum_{n=1}^{\infty} \frac{1}{n} \exp \left(-\frac{n^{2} \pi^{2} \eta_{x} t}{x_{e}^{2}}\right)\right. \\
& \left.\cdot \sin \frac{n \pi x_{f}}{2 x_{e}} \cos \frac{n \pi x_{w}}{x_{e}} \cos \frac{n \pi x}{x_{e}}\right] .
\end{aligned}
$$

The instantaneous plane function of the fracture panel perpendicular to the horizontal well can be expressed by

$$
\begin{aligned}
& S_{j}(x, y, z)=\mathrm{X}(x) \mathrm{VII}(y) \mathrm{X}(z)=\frac{x_{f} z_{f}}{x_{e} y_{e} z_{e}}[1 \\
& +\frac{4 x_{e}}{\pi x_{f}} \sum_{n=1}^{\infty} \frac{1}{n} \exp \left(-\frac{n^{2} \pi^{2} \eta_{x} t}{x_{e}^{2}}\right) \sin \frac{n \pi x_{f}}{2 x_{e}} \cos \frac{n \pi x_{w}}{x_{e}} \\
& \left.\cdot \cos \frac{n \pi x}{x_{e}}\right] \cdot\left[1+2 \sum_{n=1}^{\infty} \exp \left(-\frac{n^{2} \pi^{2} \eta_{y} t}{y_{e}^{2}}\right)\right. \\
& \left.\cdot \cos n \pi \frac{y_{w}}{y_{e}} \cos \frac{n \pi y}{y_{e}}\right] \cdot\left[1+\frac{4 z_{e}}{\pi z_{f}}\right. \\
& \cdot \sum_{n=1}^{\infty} \frac{1}{n} \exp \left(-\frac{n^{2} \pi^{2} \eta_{z} t}{z_{e}^{2}}\right) \sin \frac{n \pi z_{f}}{2 z_{e}} \cos \frac{n \pi z_{w}}{z_{e}} \\
& \left.\cdot \cos \frac{n \pi z}{z_{e}}\right] \cdot
\end{aligned}
$$

Therefore, by applying Green's function, the pressure response at any point in the reservoir result from one fracture panel can be expressed as

$$
\begin{aligned}
\Delta p(x, y, z, t) & =p_{i}-p(x, y, z, t) \\
& =\frac{1}{\phi C} \int_{0}^{t} q_{f j}(t-\tau) S_{j}(x, y, z, \tau) d \tau .
\end{aligned}
$$

Fracture Flow. Darcy's law is employed in the fracture flow. According to Darcy's law, the pressure drop is proportional to the velocity,

$$
p_{j 1}-p_{j m}=\int_{x_{j 1}}^{x_{j m}}\left(\frac{\mu}{\rho k_{f} b_{f} d}\right)_{j} q(x) d x .
$$

In fracture flows, fluid flow is considered to be onedimensional flow. The panel can be illustrated as Figure 27. The flow rate at any point in the panel can be expressed by

$$
q_{j}(x)=q_{j 1}+q_{f j}\left(x-x_{j 1}\right) .
$$

By substituting (A.8) to (A.7), we obtain

$$
\begin{aligned}
p_{j 1} & -p_{j 2} \\
= & \int_{x_{j 1}}^{x_{j 2}}\left(\frac{\mu}{\rho k_{f} b_{f} d}\right)_{j}\left[q_{j 1}+q_{f j}\left(x-x_{j 1}\right)\right] d x .
\end{aligned}
$$

The choke flow factor results from the radial flow near the wellbore entry point. An additional pressure drop is taken into account when calculating the pressure in the wellbore. For a horizontal well in the midplane of the reservoir, the pressure drop is

$$
\Delta p_{r}=\frac{q \mu \ln \left(h / 2 r_{w}\right)}{2 \pi k_{f} b_{f}}
$$

where $h$ is the fracture height and $k_{f}$ and $b_{f}$ denote fracture permeability and width, respectively. When the flow from the fracture to the reservoir is treated as linear flow, the pressure drop is

$$
\Delta p_{l}=\frac{q \mu h}{4 k_{f} b_{f} h} .
$$

Therefore, the pressure difference between radial and linear flow can be obtained by

$$
\Delta p_{s}=\Delta p_{r}-\Delta p_{l}
$$

and the choke flow factor is

$$
s_{c}=\left(\frac{h}{2 \pi x_{e}}\right)\left[\ln \left(\frac{h}{2 r_{w}}\right)-\frac{\pi}{2}\right] .
$$

Wellbore Flow. Due to the influx flow to the wellbore, the velocity profile is modified. The inflow expands and lifts the boundary layer, causing an increase of axial velocity beyond the layer. The axial velocity near the pipe wall decreases consequently. As a consequence, using no-wallflow frictional factor may cause inaccuracy in calculating frictional losses. In order to take the effect of wall roughness and fluid mixing into account, the frictional factor corrected by Ouyang et al. is employed [59].

For laminar flow, the frictional factor is

$$
f_{i}=\frac{64}{\operatorname{Re}_{i}}\left(1+0.04303 \operatorname{Re}_{w i}^{0.6142}\right)
$$


where $\mathrm{Re}_{w i}$ is the inflow Reynolds number, which can be described by $\operatorname{Re}_{w i}=q_{s i} \rho_{i} / \pi \mu_{i} . q_{s i}$ is the inflow rate per unit length. by

For turbulent flow, the frictional factor can be calculated

$$
f_{i}=f_{0 i}\left(1-0.0153 \operatorname{Re}_{w i}^{0.3978}\right),
$$

where $f_{0 i}$ is the no-wall-flow frictional factor and can be obtained by Colebrook-White correlation

$$
\frac{1}{\sqrt{f_{0 i}}}=4 \log \frac{1}{\varepsilon_{D}}+2.28-4 \log \left[\frac{4.67}{\sqrt{f_{0 i}} \operatorname{Re} \varepsilon_{D}}+1\right] .
$$

However, the no-wall-flow frictional factor is hard to get explicitly by (A.16) and iteration is needed. With the aim of simplicity, the equation was approximated [60]. The approximate equation can be expressed as follows:

$$
\frac{1}{\sqrt{f_{0 i}}}=1.14-2 \log \left(\varepsilon_{D}+\frac{21.25}{\mathrm{Re}^{0.9}}\right)
$$

The inflow pressure is $p_{\text {in }} A_{i}$, the outflow pressure is $p_{\text {out }} A_{i}$, and the shear force by the pipe wall surface is $\tau_{i} \pi D_{i} \Delta l_{i}$; the following equation is obtained consequently:

$$
\begin{gathered}
p_{\text {in }} A_{i}-p_{\text {out }} A_{i}-\tau_{i} \pi D_{i} \Delta l_{i} \\
=\rho_{\text {out }} q_{\text {out }} v_{\text {out }}-\rho_{\text {in }} q_{\text {in }} v_{\text {in }} .
\end{gathered}
$$

Equation (A.18) can be rewritten as

$$
p_{\text {in }}-p_{\text {out }}-\tau_{i} \pi \frac{D_{i}}{A_{i}} \Delta l_{i}=\rho_{\text {out }} v_{\text {out }}^{2}-\rho_{\text {in }} v_{\text {in }}^{2} .
$$

The right side of (A.19) denotes the accelerational pressure losses; namely,

$$
\Delta p_{\text {acce }}=\rho_{i}\left(v_{\text {out }}^{2}-v_{\text {in }}^{2}\right) .
$$

Therefore, the pressure drop in the wellbore can be expressed by

$$
\Delta p=\Delta p_{a c}+\Delta p_{f r}
$$

\section{Nomenclature}

Symbols

$b_{f}:$ Fracture width, $\mathrm{m}$

$C_{t}$ : Total compressibility, $\mathrm{MPa}^{-1}$

$C_{f}$ : Fracture conductivity, $\mu \mathrm{m}^{2} \cdot \mathrm{m}$

$C_{f 0}$ : Initial fracture conductivity, $\mu \mathrm{m}^{2} \cdot \mathrm{m}$ $d$ : Fracture spacing, $\mathrm{m}$

$f_{i}$ : Fraction coefficient, dimensionless

$h$ : Reservoir thickness, $m$

$k$ : Formation permeability, $\mu \mathrm{m}^{2}$

$k_{f}$ : Fracture permeability, $\mu \mathrm{m}^{2}$

$L: \quad$ Reference length, $m$

$m$ : Number of panels that a fracture is discretized into

$n$ : Fracture number

$N_{p}:$ Number of fracture panels

$p_{D}$ : Dimensionless pressure

$p_{i}: \quad$ Initial pressure, $\mathrm{MPa}$

$p_{j 1}$ : Pressure at one end of $j$ panel, $\mathrm{MPa}$

$p_{j c}$ : Pressure at the center of $j$ panel, $\mathrm{MPa}$

$Q: \quad$ Flow rate, $\mathrm{t} / \mathrm{d}$

$q_{D}$ : Dimensionless flow rate, dimensionless

$q_{f D}$ : Dimensionless flux rate, dimensionless

$r_{w}$ : Well radius, $\mathrm{m}$

$s_{c}:$ Chock flow factor, dimensionless

$t_{D}$ : Dimensionless time, dimensionless

$t_{0}$ : Initial time, $\mathrm{s}$

$x_{e}$ : Reservoir length, $\mathrm{m}$

$y_{e}$ : Reservoir width, $\mathrm{m}$.

\section{Greek Letters}

$\beta$ : Decline coefficient, dimensionless

$\rho$ : Oil density, $\mathrm{kg} / \mathrm{m}^{3}$

$\mu$ : Oil viscosity, mPa.s

$\phi$ : Porosity, dimensionless.

\section{Subscripts}

D: Dimensionless

$f$ : Fracture

$c$ : Center

$w$ : Well.

\section{Disclosure}

The present address for Harpreet Singh is National Energy Technology Laboratory, Morgantown, WV, USA.

\section{Conflicts of Interest}

The authors declare no conflicts of interest.

\section{Authors' Contributions}

Qihong Feng and Tian Xia conceived and designed the simulations; Tian Xia and Sen Wang wrote the simulation programs; Qihong Feng and Sen Wang analyzed the simulation results; Tian Xia, Sen Wang, and Harpreet Singh wrote the paper.

\section{Acknowledgments}

This work is supported by the National Program for Fundamental Research and Development of China (2015CB250905), the State Major Science and Technology 
Special Projects during the 13th Five-Year Plan (2017ZX05071007), the Program for Changjiang Scholars and Innovative Research Team in University (IRT1294), the National Postdoctoral Program for Innovative Talents (BX201600153), China Postdoctoral Science Foundation (2016M600571), and Qingdao Postdoctoral Applied Research Project (2016218).

\section{References}

[1] K. Cheng, W. Wu, S. A. Holditch, W. B. Ayers, and D. A. McVay, "Assessment of the Distribution of Technically Recoverable Resources in North American Basins," in Proceedings of the Canadian Unconventional Resources and International Petroleum Conference, Calgary, Alberta, Canada, October 2010.

[2] J. D. Hughes, "Energy: A reality check on the shale revolution," Nature, vol. 494, no. 7437, pp. 307-308, 2013.

[3] S. A. Cox, D. M. Cook, K. Dunek, R. Daniels, C. Jump, and B. Barree, "Unconventional resource play evaluation: A look at the bakken shale play of North Dakota," in Proceedings of the Unconventional Reservoirs Conference 2008, pp. 204-217, Keystone, Colo, USA, February 2008.

[4] J. Mason, "Oil production potential of the north dakota bakken," Oil \& Gas Journal, vol. 10, 2012.

[5] X. Wang and J. J. Sheng, "Effect of low-velocity non-Darcy flow on well production performance in shale and tight oil reservoirs," Fuel, vol. 190, pp. 41-46, 2017.

[6] R. Liu, B. Li, Y. Jiang, and N. Huang, "Review: Mathematical expressions for estimating equivalent permeability of rock fracture networks," Hydrogeology Journal, vol. 24, no. 7, pp. 1623-1649, 2016.

[7] A. Javaheri, H. Dehghanpour, and J. M. Wood, “Tight rock wettability and its relationship to other petrophysical properties: A Montney case study," Journal of Earth Science, vol. 28, no. 2, pp. 381-390, 2017.

[8] H. Singh, "Representative elementary volume (REV) in spatiotemporal domain: a method to find REV for dynamic pores," Journal of Earth Science, vol. 28, no. 2, pp. 391-403, 2017.

[9] C. R. Clarkson, "Production data analysis of unconventional gas wells: review of theory and best practices," International Journal of Coal Geology, vol. 109-110, pp. 101-146, 2013.

[10] A. C. Gringarten and H. J. Ramey Jr., "The use of source and green's function in solving unsteady-flow problem in reservoir," Society of Petroleum Engineers Journal, vol. 13, no. 5, pp. 285296, 1973.

[11] H. Cinco-Ley and F. Samaniego, “ Transient pressure analysis for fractured wells," Journal of Petroleum Technology, vol. 33, no. 9, pp. 1749-1766, 1981.

[12] H. Cinco-Ley and H.-Z. Meng, "Pressure transient analysis of wells with finite conductivity vertical fractures in double porosity reservoirs," in Proceedings of the SPE Annual Technical Conference and Exhibition, SPE-18172-MS, Society of Petroleum Engineers, Houston, Tex, USA, October 1988.

[13] E. Ozkan and R. Raghavan, "New solutions for well-testanalysis problems. Part 1 . Analytical considerations," SPE Formation Evaluation, vol. 6, no. 3, pp. 359-368, 1991.

[14] G. Guo, R. Evans, and M. M. Chang, "Pressure-Transient Behavior for a Horizontal Well Intersecting Multiple Random Discrete Fractures," in Proceedings of the SPE Annual Technical Conference and Exhibition, New Orleans, La, USA, September 1994.
[15] J. Wan and K. Aziz, "Multiple Hydraulic Fractures in Horizontal Wells," in Proceedings of the SPE Western Regional Meeting, Anchorage, Alaska, USA, May 1999.

[16] E. Ozkan, M. L. Brown, R. S. Raghavan, and H. Kazemi, "Comparison of Fractured Horizontal-Well Performance in Conventional and Unconventional Reservoirs," in Proceedings of the SPE Western Regional Meeting, San Jose, Calif, USA, March 2009.

[17] M. Brown, E. Ozkan, R. Raghavan, and H. Kazemi, "Practical solutions for pressure-transient responses of fractured horizontal wells in unconventional shale reservoirs," SPE Reservoir Evaluation and Engineering, vol. 14, no. 6, pp. 663-676, 2011.

[18] S. J. Al Rbeawi and T. Djebbar, "Transient Pressure Analysis of a Horizontal Well With Multiple Inclined Hydraulic Fractures Using Type-Curve Matching," in Proceedings of the SPE International Symposium and Exhibition on Formation Damage Control, Lafayette, La, USA, March 2012.

[19] R. N. Horne and K. O. Temeng, "Relative productivities and pressure transient modeling of horizontal wells with multiple fractures," in Proceedings of the 9th Middle East Oil Show \& Conference. Part 2 (of 2), pp. 563-574, Bahrain, March 1995.

[20] A. Zerzar and Y. Bettam, "Interpretation of multiple hydraulically fractured horizontal well in closed systems," in Proceedings of the Canadian International Petroleum Conference, PETSOC2004-027, Alberta, Canada, June 2004.

[21] S. Yao, F. Zeng, H. Liu, and G. Zhao, "A semi-analytical model for multi-stage fractured horizontal wells," Journal of Hydrology, vol. 507, pp. 201-212, 2013.

[22] W. Zhou, R. Banerjee, B. Poe, J. Spath, and M. Thambynayagam, "Semianalytical production simulation of complex hydraulicfracture networks," SPE Journal, vol. 19, no. 1, pp. 6-18, 2014.

[23] W. Yu, "Development of A Semi-Analytical Model for Simulation of Gas Production in Shale Gas Reservoirs," in Proceedings of the Unconventional Resources Technology Conference, Denver, Colo, USA, August 2014.

[24] P. Jia, L. Cheng, S. Huang, and H. Liu, "Transient behavior of complex fracture networks," Journal of Petroleum Science and Engineering, vol. 132, pp. 1-17, 2015.

[25] M. Al-Kobaisi, E. Ozkan, and H. Kazemi, "A Hybrid NumericalAnalytical Model of Finite-Conductivity Vertical Fractures Intercepted by a Horizontal Well," in Proceedings of the SPE International Petroleum Conference in Mexico, Puebla Pue., NM, USA, November 2004.

[26] C. M. Freeman, G. J. Moridis, D. Ilk, and T. A. Blasingame, "A Numerical Study of Performance for Tight Gas and Shale Gas Reservoir Systems," in Proceedings of the SPE Annual Technical Conference and Exhibition, New Orleans, La, USA, October 2009.

[27] C. L. Cipolla, E. Lolon, J. Erdle, and V. S. Tathed, "Modeling Well Performance in Shale-Gas Reservoirs," in Proceedings of the SPE/EAGE Reservoir Characterization and Simulation Conference, Abu Dhabi, UAE, October 2009.

[28] G. J. Moridis, T. A. Blasingame, and C. M. Freeman, "Analysis of mechanisms of flow in fractured tight-gas and shale-gas reservoirs," in Proceedings of the Latin American and Caribbean Petroleum Engineering Conference 2010, LACPEC 10, pp. 13101331, Lima, Pe, USA, December 2010.

[29] O. Olorode, C. M. Freeman, G. Moridis, and T. A. Blasingame, "High-Resolution Numerical Modeling of Complex and Irregular Fracture Patterns in Shale-Gas Reservoirs and Tight Gas Reservoirs," SPE Reservoir Evaluation \& Engineering, vol. 16, no. 04, pp. 443-455, 2013. 
[30] W. Yu, B. Gao, and K. Sepehrnoori, "Numerical Study of the Impact of Complex Fracture Patterns on Well Performance in Shale Gas Reservoirs," Journal of Petroleum Science Research, vol. 3, no. 2, p. 83, 2014.

[31] S. N. Shah, M. C. Vincent, R. X. Rodriquez, and T. T. Palisch, "Fracture Orientation And Proppant Selection For Optimizing Production In Horizontal Wells," in Proceedings of the SPE Oil and Gas India Conference and Exhibition, Mumbai, India, January 2010.

[32] J. Weaver, M. Parker, D. van Batenburg, and P. Nguyen, "Fracture-related diagenesis may impact conductivity," SPE Journal, vol. 12, no. 3, pp. 272-281, 2007.

[33] M. C. Vincent, "Refracs - Why do they work, and why do they fail in 100 published field studies?" in Proceedings of the SPE Annual Technical Conference and Exhibition 2010, ATCE 2010, pp. 2237-2281, Florence, Italy, September 2010.

[34] M. C. Vincent, "Restimulation of unconventional reservoirs: When are refracs beneficial?" Journal of Canadian Petroleum Technology, vol. 50, no. 6, pp. 36-52, 2011.

[35] B. McDaniel, "Conductivity Testing of Proppants at High Temperature and Stress," in Proceedings of the SPE California Regional Meeting, Oakland, Calif, USA, April 1986.

[36] S. Cobb and J. Farrell, "Evaluation of Long-Term Proppant Stability," in Proceedings of the International Meeting on Petroleum Engineering, Beijing, China, March 1986.

[37] P. Handren and T. Palisch, "Successful hybrid slickwater-fracture design evolution: an east texas cotton valley taylor case history," SPE Production and Operations, vol. 24, no. 3, pp. 415-424, 2009.

[38] Y.-L. Zhao, L.-H. Zhang, J.-X. Luo, and B.-N. Zhang, "Performance of fractured horizontal well with stimulated reservoir volume in unconventional gas reservoir," Journal of Hydrology, vol. 512, pp. 447-456, 2014.

[39] E. Stalgorova and L. Mattar, "Practical Analytical Model To Simulate Production of Horizontal Wells With Branch Fractures," in Proceedings of the SPE Canadian Unconventional Resources Conference, Calgary, Alberta, Canada, November 2012.

[40] W. Luo, C. Tang, and X. Wang, "Pressure transient analysis of a horizontal well intercepted by multiple non-planar vertical fractures," Journal of Petroleum Science and Engineering, vol. 124, pp. 232-242, 2014.

[41] C. Guo, J. Xu, M. Wei, and R. Jiang, "Pressure transient and rate decline analysis for hydraulic fractured vertical wells with finite conductivity in shale gas reservoirs," Journal of Petroleum Exploration and Production Technology, vol. 5, no. 4, pp. 435-443, 2015.

[42] H. Mukherjee and M. J. Economides, "Parametric comparison of horizontal and vertical well performance," SPE Formation Evaluation, vol. 6, no. 2, pp. 209-216, 1991.

[43] C. T. Montgomery and R. Steanson, "Proppant selection: the key to successful fracture stimulation," Journal of Petroleum Technology, vol. 37, no. 12, pp. 2163-2172, 1985.

[44] S. C. Yu, "Evaluation of long term fracture conductivity for ceramic proppant and Lanzhou sand," Oil Drilling \& Production Technology, vol. 11, pp. 1-7, 1987.

[45] C. Y. Jiao, S. L. He, H. J. Zhang, and H. X. Liu, "Southwest Petroleum University," in Southwest Petroleum University, vol. 33, pp. 107-110, 2011.

[46] G. O. Brown, "The History of the Darcy-Weisbach Equation for Pipe Flow Resistance," in Proceedings of the Environmental and Water Resources History Sessions at ASCE Civil Engineering
Conference and Exposition 2002, pp. 34-43, Washington, D.C., USA, 2003.

[47] H. S. Bae, S. Pyun, W. Chung, S.-G. Kang, and C. Shin, "Frequency-domain acoustic-elastic coupled waveform inversion using the Gauss-Newton conjugate gradient method," Geophysical Prospecting, vol. 60, no. 3, pp. 413-432, 2012.

[48] CMG IMEX User's Guide, 2012. Computer Modelling Group Ltd., Calgary, Alberta, Canada.

[49] M. Fisher, J. Heinze, C. Harris, B. Davidson, C. Wright, and K. Dunn, "Optimizing Horizontal Completion Techniques in the Barnett Shale Using Microseismic Fracture Mapping," in Proceedings of the SPE Annual Technical Conference and Exhibition, Houston, Tex, USA, September 2004.

[50] C. L. Cipolla, X. Weng, M. G. Mack et al., "Integrating Microseismic Mapping and Complex Fracture Modeling to Characterize Hydraulic Fracture Complexity," in Proceedings of the SPE Hydraulic Fracturing Technology Conference, The Woodlands, Tex, USA, January 2011.

[51] S. Jain, M. Soliman, A. Bokane et al., "Proppant Distribution in Multistage Hydraulic Fractured Wells: A Large-Scale InsideCasing Investigation," in Proceedings of the SPE Hydraulic Fracturing Technology Conference, The Woodlands, Tex, USA, February 2013.

[52] N. P. Roussel and M. M. Sharma, "Optimizing Fracture Spacing and Sequencing in Horizontal-Well Fracturing," SPE Production \& Operations, vol. 26, no. 02, pp. 173-184, 2011.

[53] V. R. Penmatcha and K. Aziz, "Comprehensive reservoir/ wellbore model for horizontal wells," in Proceedings of the 1998 SPE India Oil and Gas Conference and Exhibition, pp. 191-204, New Delhi, India, April 1998.

[54] A. H. Kabir and J. A. Vargas, "Accurate Inflow Profile Prediction of Horizontal Wells Using a Newly Developed Coupled Reservoir and Wellbore Analytical Models," in Proceedings of the SPE Oil and Gas India Conference and Exhibition, The Woodlands, Tex, USA, February 2009.

[55] J. Cai, W. Wei, X. Hu, R. Liu, and J. Wang, "Fractal characterization of dynamic fracture network extension in porous media," Fractals, vol. 25, no. 02, 2017.

[56] J. Cai and S. Sun, "Fractal analysis of fracture increasing spontaneous imbibition in porous media with gas-saturated," International Journal of Modern Physics C, vol. 24, no. 8, Article ID 1350056, 2013.

[57] J. Cai, S. Guo, L. You, and X. Hu, "Fractal analysis of spontaneous imbibition mechanism in fractured-porous dual media reservoir," Acta Physica Sinica, vol. 62, 2013.

[58] X. Wang, L. Sun, R. Zhu et al., "Application of charging effects in evaluating storage space of tight reservoirs: A case study from Permian Lucaogou Formation in Jimusar sag, Junggar Basin, NW China," Petroleum Exploration and Development, vol. 42, no. 4, pp. 516-524, 2015.

[59] L.-B. Ouyang, S. Arbabi, and K. Aziz, "A Single-Phase WellboreFlow Model for Horizontal Vertical, and Slanted Wells," SPE Journal, vol. 3, no. 2, pp. 124-133, 1998.

[60] P. K. Swamee and A. K. Jain, "Explicit equations for pipe-flow problems," Journal of the Hydraulics Division, vol. 102, no. 5, pp. 657-664, 1976. 

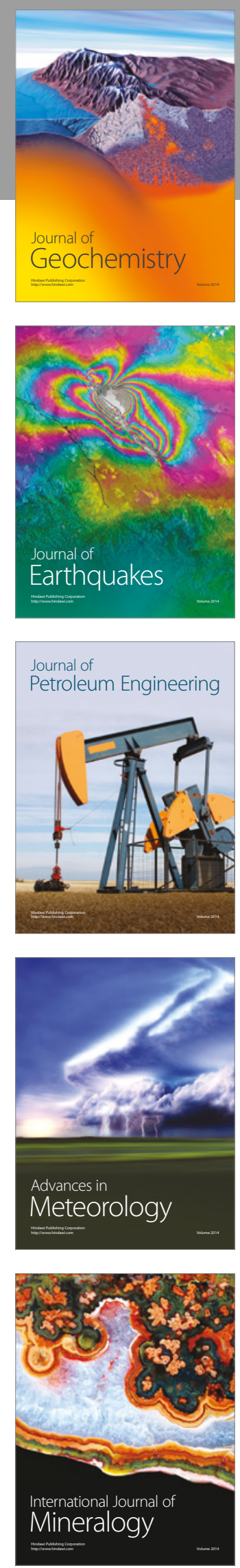
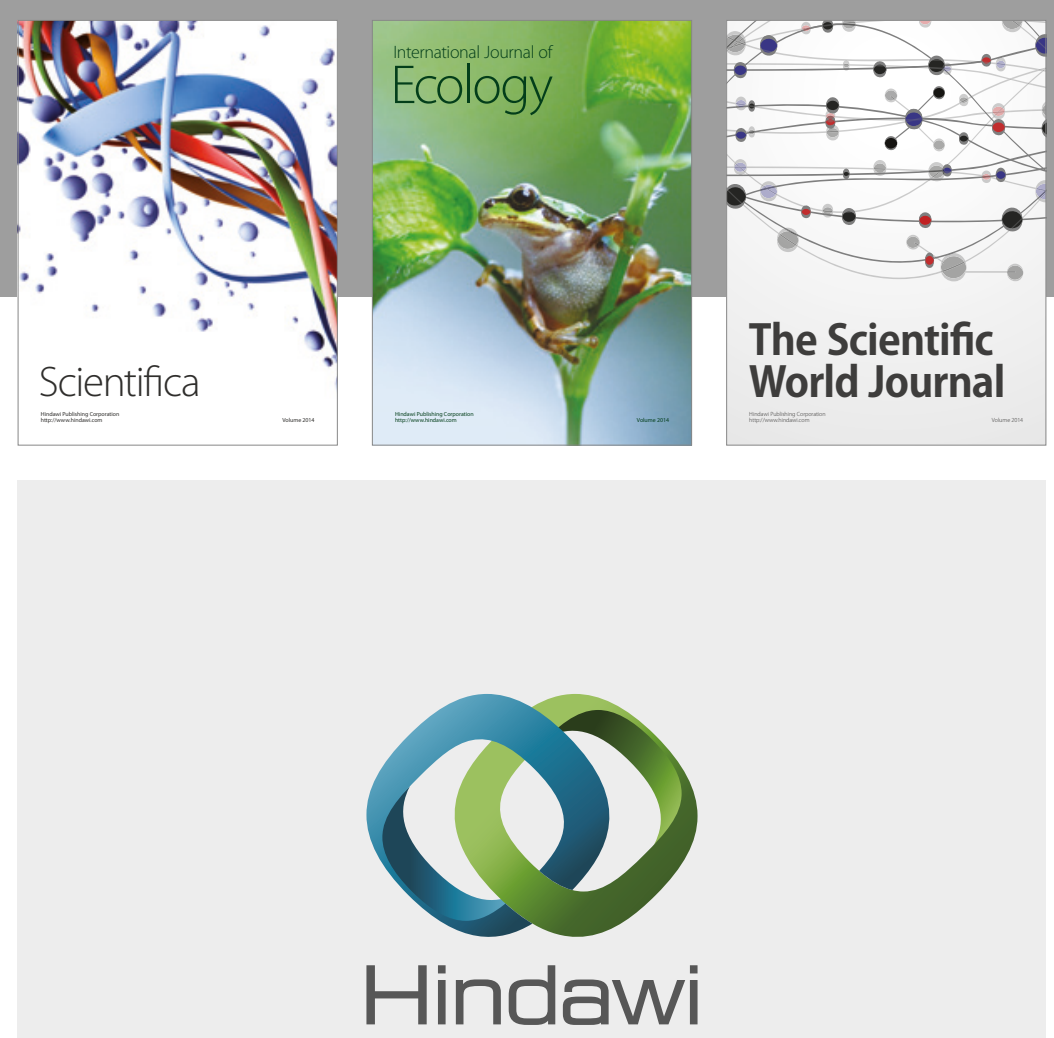

Submit your manuscripts at

https://www.hindawi.com
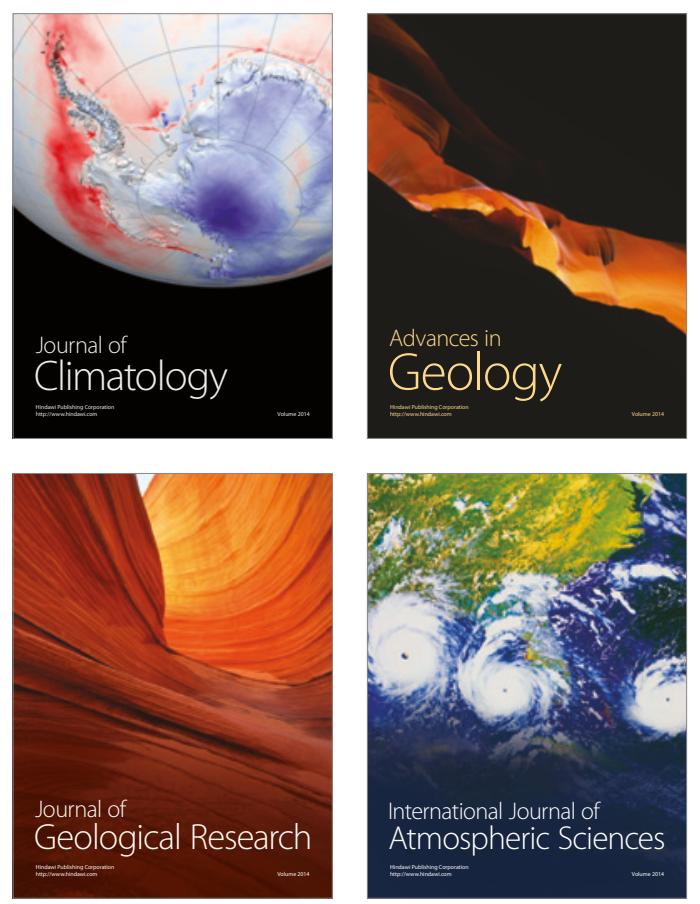

The Scientific

World Journal
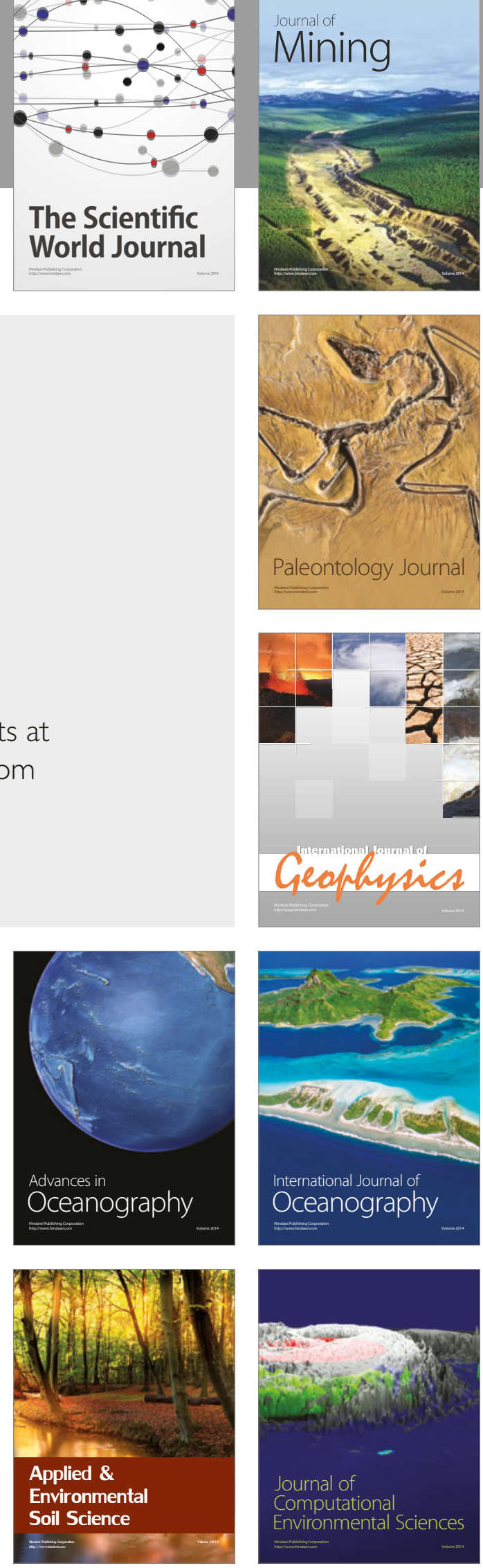